
\title{
R Research Soure \\ Research on Ultrasonic-Assisted Multi-Point Stretch Bending Process of Aluminum Profile
}

\author{
Yi Li \\ Jilin University \\ Zhiheng Hu \\ Jilin University \\ Jicai Liang \\ Jilin University \\ Ce Liang ( $\nabla$ liangce@jlu.edu.cn ) \\ Jilin University
}

\section{Research Article}

Keywords: ultrasonic vibration, multi-point bending, profile, spring-back, finite element simulation

Posted Date: May 25th, 2021

DOl: https://doi.org/10.21203/rs.3.rs-538098/v1

License: (9) This work is licensed under a Creative Commons Attribution 4.0 International License. Read Full License

Version of Record: A version of this preprint was published at The International Journal of Advanced Manufacturing Technology on December 3rd, 2021. See the published version at https://doi.org/10.1007/s00170-021-08408-1. 


\title{
Research on Ultrasonic-assisted Multi-point Stretch Bending Process of Aluminum Profile
}

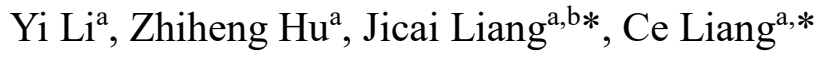 \\ a Key Laboratory of automobile Materials, Ministry of Education, and College of \\ Materials Science and Engineering, Jilin University, Changchun 130025, China \\ E-mail: liangce@jlu.edu.cn; \\ b Roll Forging Research Institute, Jilin University, Changchun, 130025, Jilin, China
}

Abstract: The tensile and bending process of asymmetric L-shaped aluminum alloy profile is studied by the Abaqus software using the finite element numerical simulation method. The geometric parameters of the ultrasonic-assisted vibration multi-point die (UMPD), and the law of influence on the stress-strain and spring-back of the L-section profile after bending are studied. The results show that the UMPD can reduce the forming stress of the profile during plastic deformation, and the stress-strain distribution of the aluminum profile is more uniform. The changes in the ultrasonic vibration frequency and amplitude of the mold are beneficial to reduce the spring-back of aluminum profiles. The ultrasonic process parameters with a vibration frequency of $20 \mathrm{kHz}$ and an amplitude of $0.02 \mathrm{~mm}$ have the best effect on suppressing spring-back, which is reduced by $20.6 \%$ compared to the case of no ultrasonic application. Finally, it is verified by experiments that the experimental results are basically consistent with the simulation results, and the changing trend of spring-back deformation is consistent.

Keywords: ultrasonic vibration; multi-point bending; profile; spring-back; finite element simulation

\section{Introduction}

With the development of the automobile and rail transit industry, higher requirements are put forward for the lightweight of automobiles [1]. Aluminum alloys have the advantages of low density, high strength, good impact resistance, and easy recycling. They are widely used in the manufacture of automotive safety components 
and framed bodies [2-3]. The stretch-bending process has the advantages of high forming accuracy and low spring-back, which can be used for frame parts with high forming accuracy. Multi-point forming is a new flexible forming technology that can quickly adjust the configuration surface of the basic body according to the target shape of the part to construct a forming surface [4], thus realizes moldless, rapid, and flexible forming. Multi-point forming technology and equipment have been widely used in recent years, mainly used for the three-dimensional forming of sheet metal [5-7]. The combining of the multi-point forming technology with the stretch-bending process of aluminum alloy profiles can not only save the time and expense of traditional stretch-bending mold design, manufacturing, and debugging, but also shorten the production cycle of formed parts, and greatly save costs [8].

In metal plastic forming, vibration assisted forming technology is a new type of metal processing technology with significant characteristics. Compared with the traditional plastic processing method, it has the following characteristics: reduce the yield limit of the material; reduce the deformation resistance; increase the plasticity and fracture limit; and improve the mechanical properties of the material. For high-strength, high-hardness materials, it can effectively improve its plastic forming performance and achieve good processing results [9]. At present, the view on vibration plastic processing is divided into two aspects of volume effect and surface effect. The volume effect shows that vibration can reduce the forming force and flow stress of the material; and in terms of surface effect, the superposition of vibration reduces the friction between the mold and the workpiece. The two effects work together to obtain better processing quality and excellent dimensional accuracy. With the continuous improvement of metal plastic processing technology, the theory and application of vibration are also continuously improved and expanded [10, 11]. Dutta et al. [12-13] conducted ultrasonic-assisted tensile tests on DC04 low carbon steel and found that the introduction of ultrasound significantly changed the grain orientation. Wen Tong [14] analyzed the mechanical properties of magnesium alloy under ultrasonic vibration and found that ultrasonic vibration can reduce the deformation resistance of magnesium alloy AZ31 and increase the plasticity. However, as the vibration energy continues to 
increase, after exceeding a certain value, AZ31 magnesium alloy has hardened, but this hardening only reduces the plasticity of the material, and the deformation resistance does not improve. Dawson et al. [15] obtained some conclusions in terms of surface effects. When the vibration-assisted machining is superimposed, the mold and the workpiece are separated at some moments, and the superposition of vibration causes the vector of friction to be reversed. Sometimes, the friction force can promote the deformation, and it may also be accompanied by a local thermal effect. The vibration makes the surface temperature of the workpiece rise, so that the lubrication is improved, thereby improving the processing quality of the workpiece.

This paper conducts a study on the phenomenon of large spring-back and uneven stress distribution in aluminum profiles in the traditional stretch-bending process. The combination of ultrasonic vibration technology and multi-point stretch-bending forming process is also applied to aluminum materials. Numerical simulations verify that the ultrasonic-assisted vibration on the point dies has more effect on the stretch-bending forming of aluminum alloy profiles. Firstly, a finite element model is established based on the parameters and dimensions of the mold and the "L" profile in the test. Secondly, the numerical simulation is performed on the bending and spring-back processes to analyze the effects of vibration frequency and amplitude on the forming accuracy, thus further determining the stress-strain distribution and spring-back deformation law of "L"-shaped profile in stretch-bending forming. After comparing the numerical simulation results and the experimental results, it is found that the ultrasonic vibration assisted process can help reduce the spring-back value of the preform in stretch-bending forming.

\section{Ultrasonic-assisted multi-point stretch-bending process and finite element simulation}

\subsection{Multi-point stretch-bending forming and ultrasonic vibration technology}

The basic principle of multi-point stretch-bending forming is to discretize the traditional integral stretch-bending forming die into a series of basic units (or die head body) with regular arrangement and adjustable profile. The position of each basic unit 
can be adjusted independently. Changing the position of each basic unit will change the forming surface, which is equivalent to reconstructing the molding profile. The forming processes are as follows. Based on adjusting the multi-point dies (MPD), pre-stretching is realized under the axial traction of the clamp to stretch the profile to a plastic state. Then, the parison of the workpiece is gradually fitted to the mold in the horizontal direction under the action of the clamp, so that the profile can be bent and deformed in the horizontal direction. Finally, the clamp continues to apply the compensating tension along the tangent direction of the profile at the last position in the space, which can further reduce Spring-back defect of profile. The ultrasonic-assisted multi-point stretch-bending forming equipment is shown in Fig 1. The vibration device includes an ultrasonic generator, an ultrasonic transducer, a horn and a multi-point die head. The ultrasonic generator converts a certain alternating current into a certain power high-frequency alternating current signal. Then, the high-frequency alternating current signal is converted by the transducer into a mechanical oscillation with a larger frequency. The vibration amplitude with higher frequency is enlarged by the horn, and then transmitted to the MPD connected with the horn, and finally, the ultrasonic vibration is applied to the processed parison through the tool head.
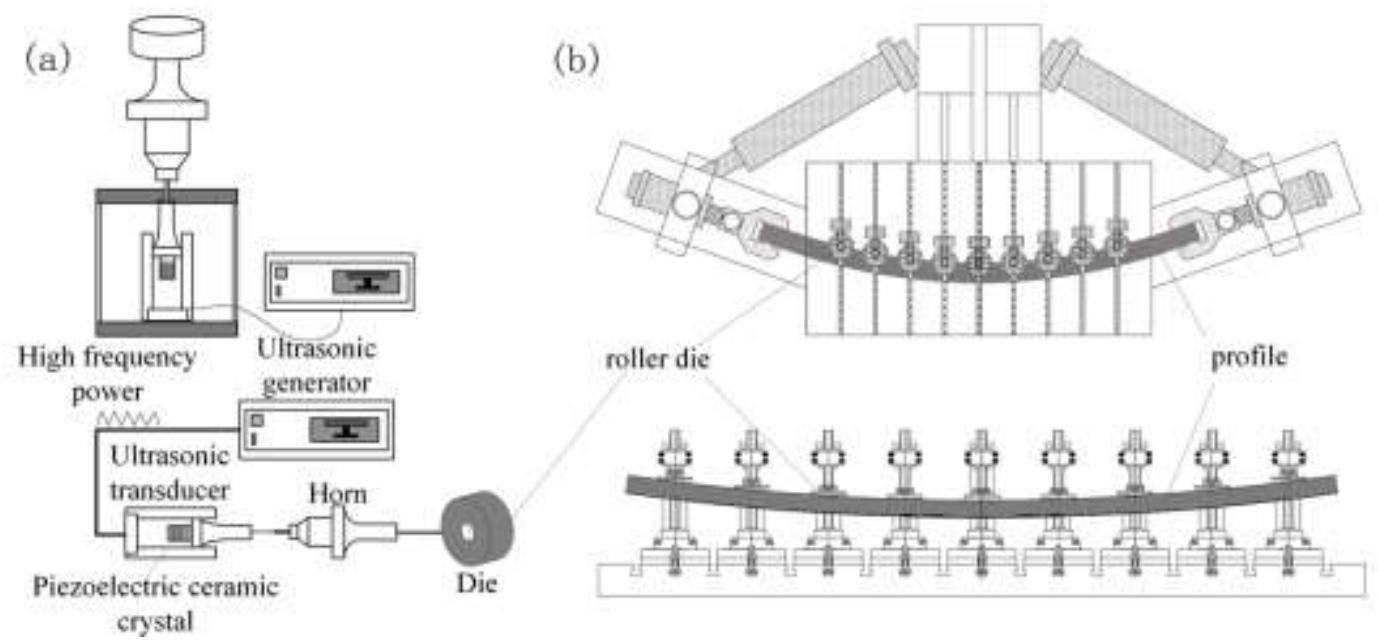

Fig. 1 Schematic diagram of ultrasonic-assisted multi-point stretch-bending forming equipment: (a) Ultrasonic device and ultrasonic vibration principle; (b) 


\subsection{Material model}

The profile material is aluminum alloy AA6082. The material parameters of aluminum profiles and its cross-sectional size are shown in Table 1 and Fig 2. In the material model, it is assumed that the material follows the Von-Mises yield criterion and the Prandtl reuse flow law, and the elastoplastic constitutive behavior and the strain hardening model are isotropic.

Table 1 AA6082 material parameters

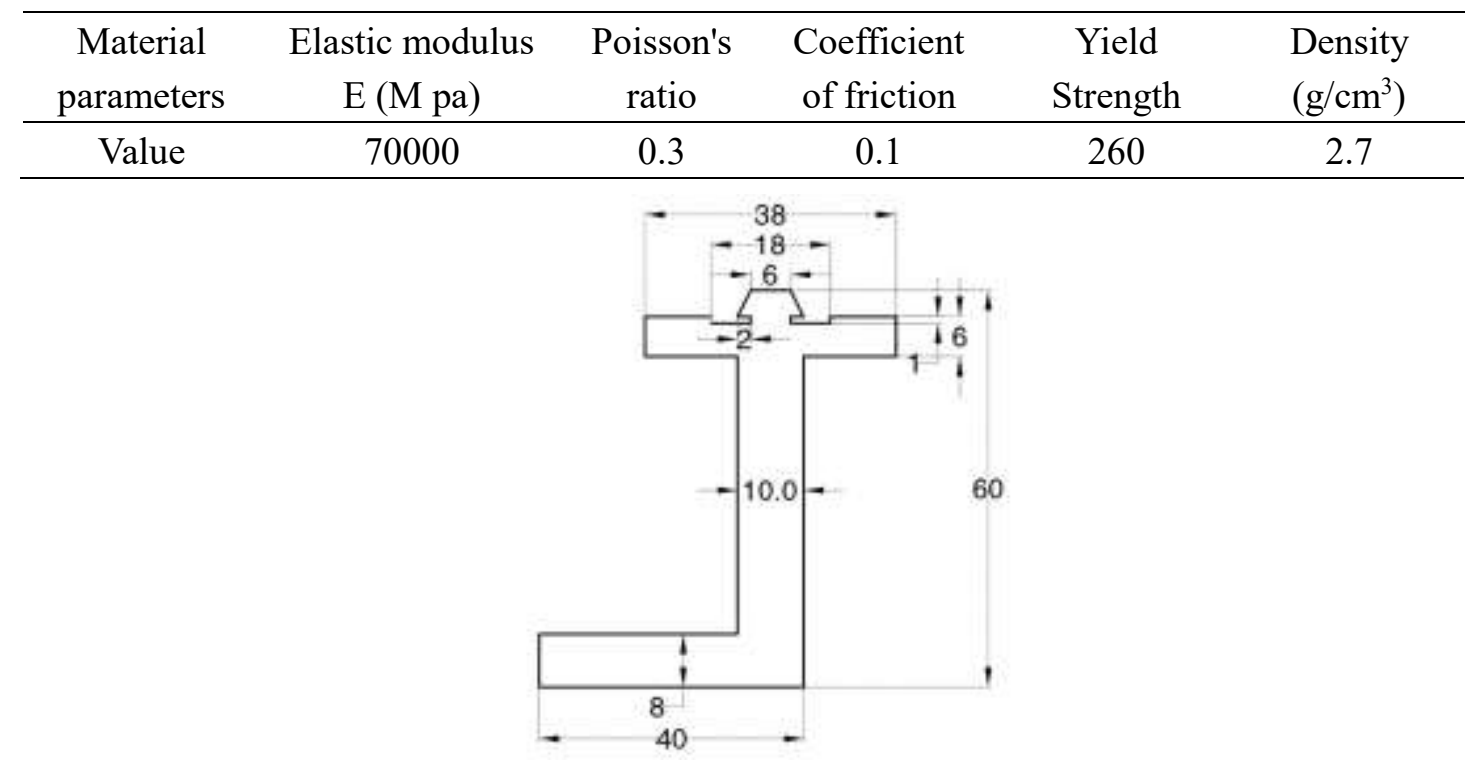

Fig. 2 Geometric shape and size of L profile

\subsection{Establishment of finite element model}

In this work, ABAQUS2019 is used for finite element simulation and numerical simulation. The ABAQUS/explicit dynamic explicit algorithm is used to simulate the stretch-bending process of the profile; the ABAQUS/standard static implicit algorithm is used to simulate the spring-back process. The finite element model is composed of profiles, clamps and MPDs. The clamps play the role of applying tension and bending moments. C3D8R is selected as the solid unit of aluminum profile in the simulation process. C3D8R is a hexahedral solid element with 8 nodes that reduces the integral linearly. It is suitable for large strains and deformations. Since rigid elements are mainly used to simulate components that can be fixed or moved, UMPDs and clamps are simulated by the rigid element body R3D4. The rigid body element does not calculate the element level in the simulation calculation, so the calculation time can be 
significantly shortened. Fig 3 shows the main components of the finite element model.

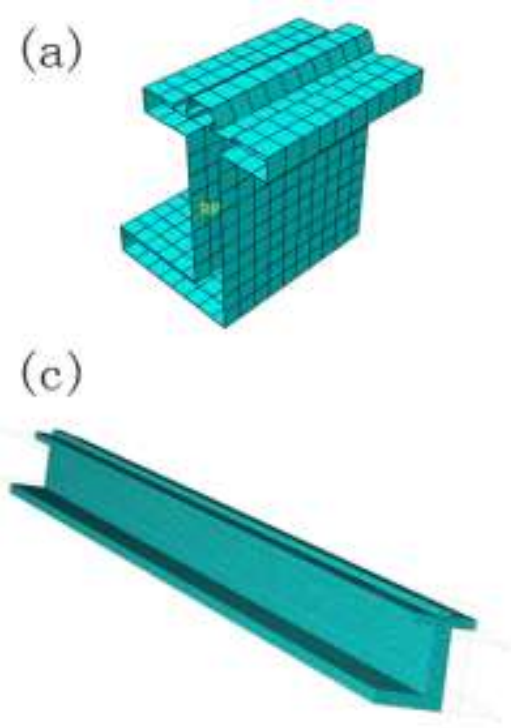

(b)

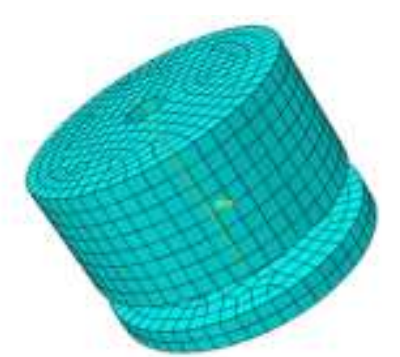

(d)

Fig. 3 Main components: (a) clamp; (b) die; (c) aluminum profifile; (d) assembly

Since the actual processing of the profile is symmetrical, half of the profile is taken for modeling analysis. The boundary condition set at the symmetrical section is the symmetrical constraint in the z-axis direction. The method of applying the load selects the displacement and time, and the clamp equation of the horizontally curved trajectory is:

$$
\begin{gathered}
\Delta x=\left(L_{0}+\delta\right)-\left\{R_{1} \times \sin \alpha+\left[\left(L_{0}+\delta\right)-R_{1} \times \alpha\right] \times \cos \alpha+d \times \sin \alpha\right\} \\
\Delta y=d+R_{1} \times(1+\cos \alpha)+\left[\left(L_{0}+\delta\right)-R_{1} \times d\right] \times \sin \alpha-d \times \cos \alpha
\end{gathered}
$$

Where, $\Delta x$ is the distance the fixture moves along the $\mathrm{X}$-axis, $\Delta y$ is the distance the fixture moves along the $\mathrm{Y}$-axis, $L_{0}$ is half the length of the profile; $R_{1}$ is the horizontal bending radius; $\delta$ is the pre-stretching amount; $\alpha$ is the instantaneous wrap angle during the filming process, $d$ is the distance from the reference point of the clamp to the bottom surface of the profile. The trajectory diagram of the clamp horizontal bending is shown in Fig 4. 


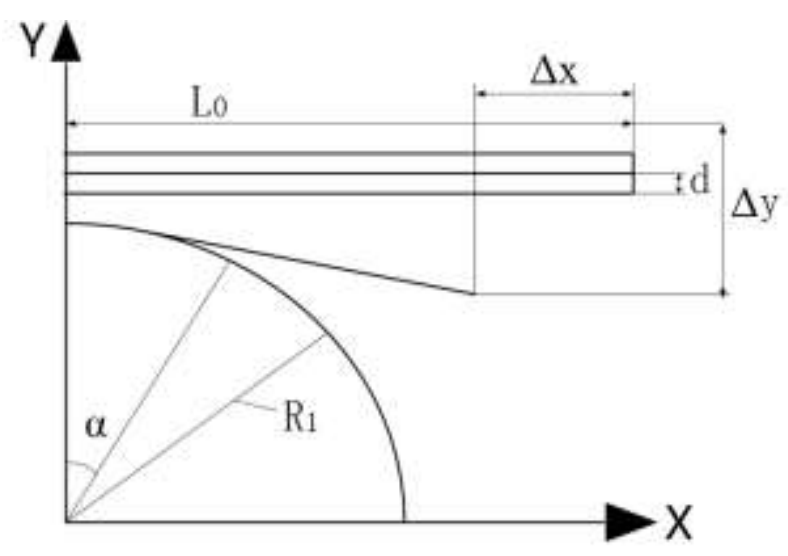

Fig. 4 Profile movement trajectory

When other factors are ignored and only elastic deformation and plastic deformation are considered as the factors affecting metal deformation, the constitutive relationship model is shown in Fig 5.

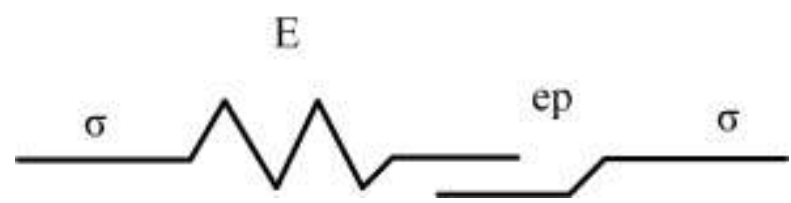

Fig. 5 Elastic-plastic model

When the strain rate is relatively low, the strained relationship in the plastic processing of low-frequency vibration metal materials is shown in Fig. 6, which is mainly represented by the elastoplastic constitutive model. Where $E$ is the modulus of elasticity; $E$ ' is the strengthening modulus; $\sigma_{\mathrm{s}}$ is the yield stress.
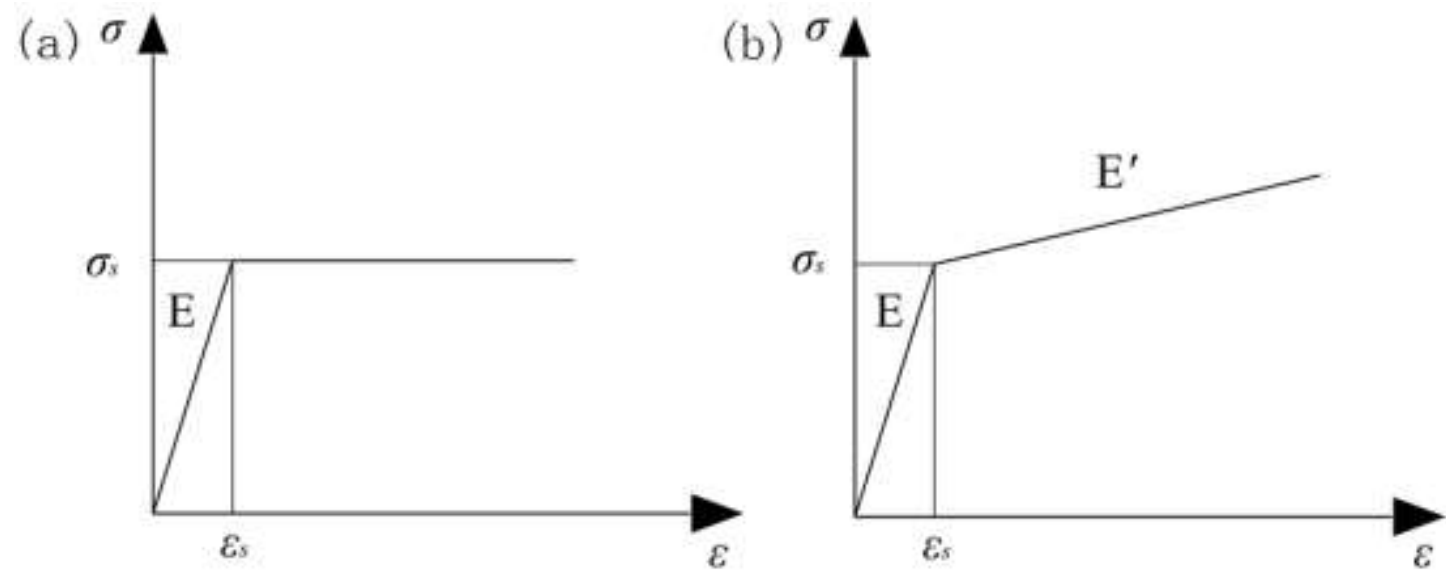

Fig. 6 The stress-strain relationship between an ideal elastoplastic body (a) and a linearly strengthened elastoplastic body (b)

The yield condition for the linear strengthening elastoplastic model can be expressed from the following expression: 
Initial yield condition:

$$
|\sigma|=\sigma_{s}
$$

Subsequent yield condition:

$$
|\sigma|=\sigma_{s}{ }^{\prime}
$$

The constitutive relationship of the linear strengthening elastoplastic model is as follows:

Initial yield:

$$
\begin{gathered}
\sigma=E \sin \varepsilon \\
\sigma=\left[\sigma_{s}+E^{\prime}\left(|\varepsilon|-\varepsilon_{s}\right)\right] \sin \varepsilon
\end{gathered}
$$

Load after initial yield:

Unload after initial yielding or apply load after unloading but fail to reach the subsequent yield point:

$$
\triangle \sigma=E \triangle \varepsilon
$$

$$
\sin \varepsilon=\left\{\begin{array}{cc}
1 & \varepsilon>0 \\
0 & \varepsilon<0 \\
-1 & \varepsilon=0
\end{array}\right.
$$

And for the ideal elastic shaping model, it can make the above formula $\sigma_{s}^{\prime}=\sigma_{s}$, $E^{\prime}=0$

In the viscoplastic stage, considering the subsequent yield, strain history, strain rate history, and elastic strain, the following equations can be obtained to solve the dynamic response of viscoelastic plastic:

$$
\begin{gathered}
\sigma(t)=\frac{\eta_{1} \eta_{2}}{\eta_{1}+\eta_{2}}\left[\dot{\varepsilon}(t)+\frac{E \varepsilon_{e}(t)}{\eta_{1}}+\frac{\sigma_{s p}+B_{0}\left(\varepsilon(t)-\varepsilon_{0}-\varepsilon_{e}(t)\right)}{\eta_{2}}\right] \\
\dot{\varepsilon}(t)=\dot{\varepsilon}_{0}+2 \pi f A \cos (2 \pi f t) \\
\varepsilon(t)=\dot{\varepsilon}_{0} t+A \sin (2 \pi f t) \\
\varepsilon_{e}(t)=\frac{\sigma_{0}}{E}\left(1-e^{\frac{-E t}{\eta_{1}}}\right)
\end{gathered}
$$

Where, $\varepsilon(\mathrm{t})$ is the time history of strain; $\dot{\varepsilon}(\mathrm{t})$ is the time history of strain rate; $\varepsilon, \varepsilon_{e}$ and $\varepsilon_{0}$ are respectively the total strain, elastic strain, and viscous strain of the viscoplastic part; $\sigma, \sigma_{\mathrm{sp}}$ and $\sigma_{0}$ are respectively the total stress, plastic stress, and viscous stress of the viscoplastic part.

Considering that the material is in the process of repeated loading and unloading, the residual strain $\varepsilon_{0}$ should be included in the total strain. As the time $t$ increases, the term $e^{\frac{-E t}{\eta_{1}}}$ approaches 0 , so the above formula can be simplified to:

$$
\sigma=\frac{\eta_{1}}{\eta_{1}+\eta_{2}} B_{0} \varepsilon+\frac{\eta_{1} \eta_{2}}{\eta_{1}+\eta_{2}} \dot{\varepsilon}+\sigma_{s}
$$




\section{Numerical simulation results and discussion}

In the process of flexible multi-point stretching and bending, the ultrasonic vibration parameter of the mold has a great influence on the stress-strain distribution and spring-back of the profile deformation process. Therefore, it is very important to select the appropriate amplitude and frequency of the ultrasonic-assisted vibration multi-point dies (UMPD). The forming process is divided into three steps, including pre-stretching, horizontal bending and complementary stretching. The amount of pre-stretching and supplementary stretching is $1 \%$, and the bending angle is 30 degrees. The horizontal spacing of the die heads is set to $200 \mathrm{~mm}$, and the number of die heads is 15 . When the diameter of the die head is $85 \mathrm{~mm}$, the curvature of the die head is consistent with the target shape. The length of the profile is $3100 \mathrm{~mm}$, and the friction coefficient between the profile and the die head is 0.1 .

Under $0.02 \mathrm{~mm}$ amplitude, the ultrasonic vibration frequency of multi-point mold is $20,22,24,26$, and $28 \mathrm{kHz}$ for finite element simulation analysis. Fig 7 shows the stress distribution diagram of the profile after stretch-bending forming without ultrasonic and $20 \mathrm{kHz}$ ultrasonic vibration frequency. Fig 8 shows the equivalent strain distribution diagram of the profile after stretch-bending forming without ultrasonic and $20 \mathrm{kHz}$ ultrasonic vibration frequency.

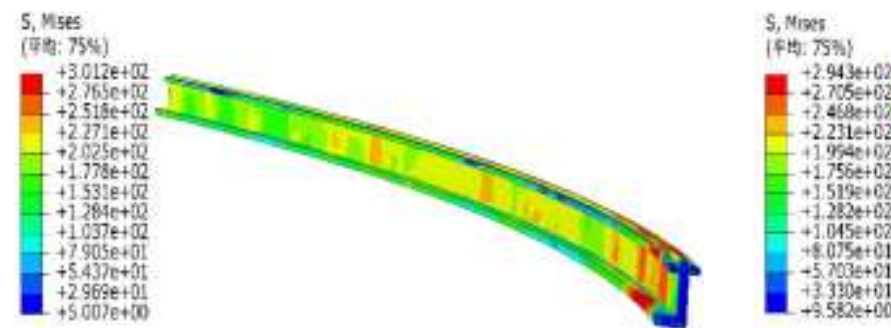

(a)

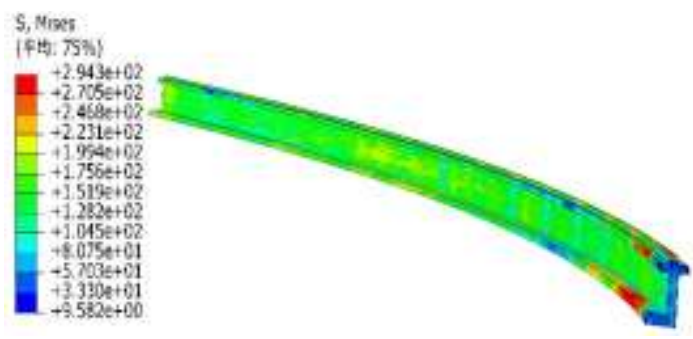

(b)

Fig. 7 Stress distribution of the model after stretching and bending: (a) MPD forming; (b) UMPD forming

In fact, the maximum stress value of the profile is located near the clamp, and subsequent processing needs to be removed. Therefore, only the effective forming area is selected for analysis. Fig 7 (a) is the stress diagram after the MPD stretch and bending the profile. The maximum stress is $301.2 \mathrm{MPa}$, the minimum stress value is 
5.007 MPa, and the stress difference is $296.193 \mathrm{MPa}$. In Fig 7(b), the stress change range of UMPD after bending of the profile is $9.582-294.3 \mathrm{MPa}$, and the stress difference is $284.718 \mathrm{MPa}$. When the MPD introduces ultrasonic vibration, the stress difference decreases, which means that the stress distribution is more uniform, that is, the stress concentration phenomenon becomes less. Fig 8 shows that the equivalent plastic strain distribution of aluminum profiles is more uniform after ultrasonic-assisted bending.

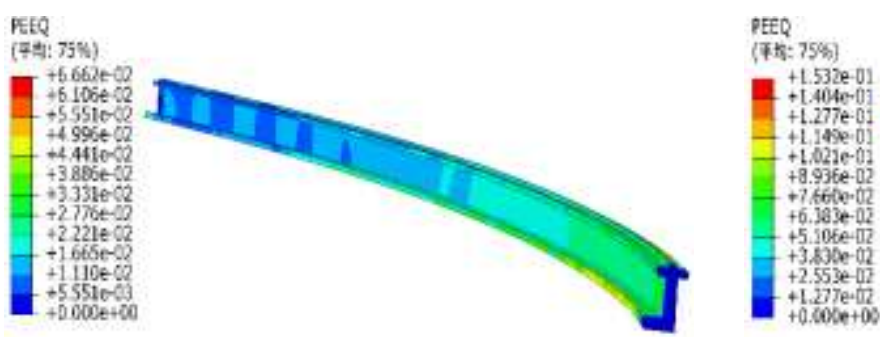

(a)

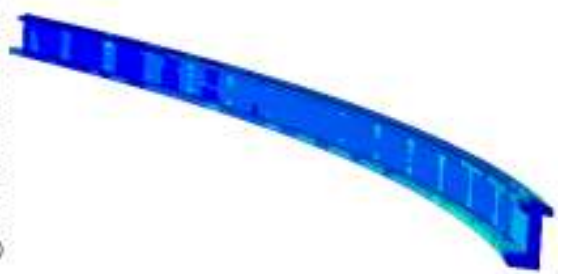

(b)

Fig. 8 The strain distribution of the model after stretching and bending: (a) MPD forming; (b) UMPD forming

When the ultrasonic vibration frequency changes, the maximum stress and maximum equivalent plastic strain are shown in Fig 9. It can be seen from Fig 9 that the maximum stress of the ordinary MPD profile after stretching and bending is 340.9 $\mathrm{MPa}$. When the ultrasonic assisted process is added and the vibration frequency is changed, the maximum stress is $330.9,330.7,326.8,325.2$, and $327.3 \mathrm{MPa}$ in sequence. UMPD can greatly reduce the maximum stress of "L" aluminum profile forming, and the best vibration frequency is $26 \mathrm{kHz}$.

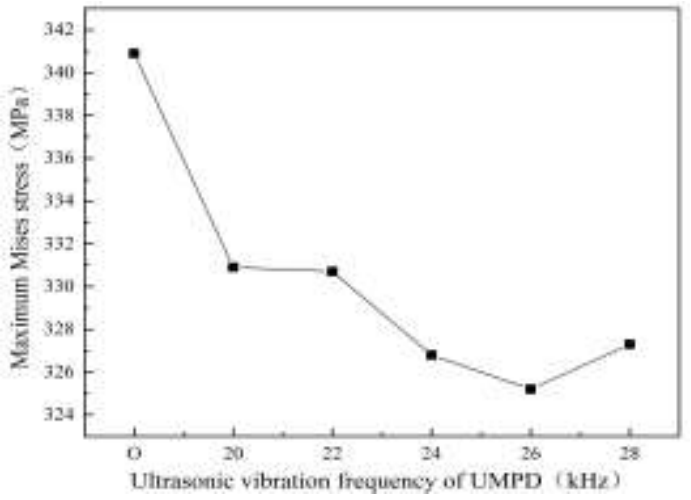

(a)

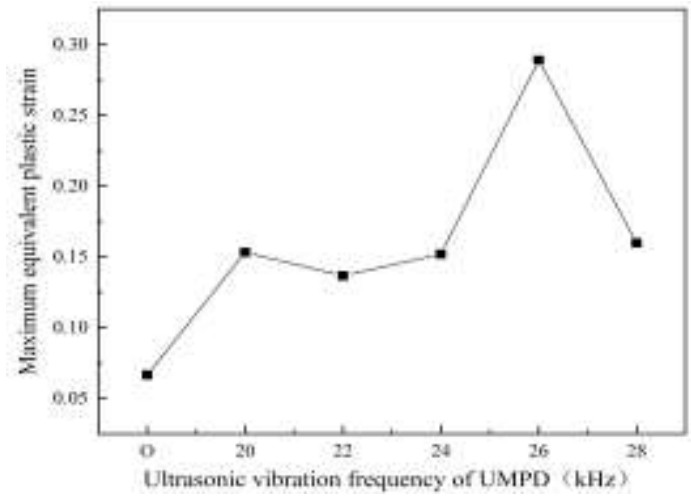

(b)

Fig. 9 Maximum stress and maximum equivalent plastic strain when the ultrasonic 
vibration frequency of the UMPD changes: (a) The relationship between the maximum stress and the vibration frequency of the UMPD; (b) The relationship between the maximum equivalent plastic strain and the vibration frequency of the UMPD

The maximum stress and maximum equivalent plastic strain when the ultrasonic amplitude of the UMPD changes are shown in Fig 10. When the amplitude of the UMPD is $0.01,0.015,0.02,0.025$, and $0.03 \mathrm{~mm}$, the maximum stress of the profile is also greatly reduced compared with the ordinary MPD from $340.9 \mathrm{MPa}$ to 329, 332.6, 330.9, 336.6, and $334 \mathrm{MPa}$. After the vibration frequency of the UMPD is changed, the most effective amplitude is $0.01 \mathrm{~mm}$. Regardless of the change in amplitude or frequency, the maximum equivalent plastic strain of the traditional MPD is improved. This shows that under certain conditions, ultrasonic vibration can improve the forming ability of the material and produce greater plastic deformation. Although the traditional MPD is more convenient and faster than the previous integral mold, the position of the mold will also cause the stress concentration of the profile and affect the forming quality, especially in some serious cases, it will form defects such as indentation [16-17]. After the introduction of ultrasonic vibration, the UMPD makes the profile stress and equivalent plastic strain distribution after stretching and bending more uniform, so that the contact position of the parison and the UMPD will not appear distortion and defects.

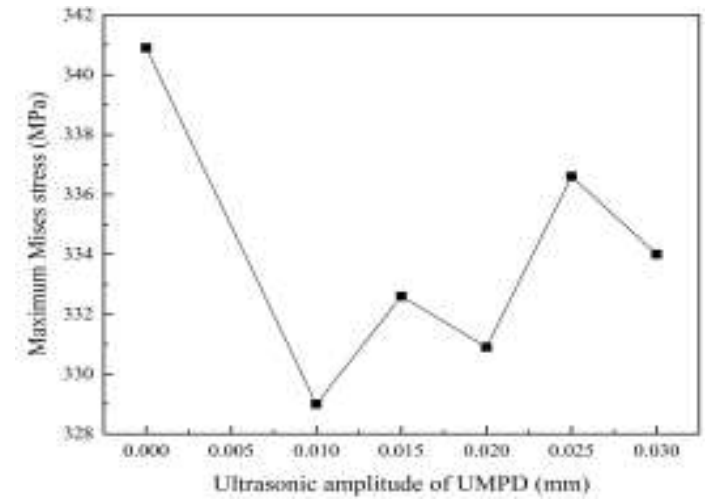

(a)

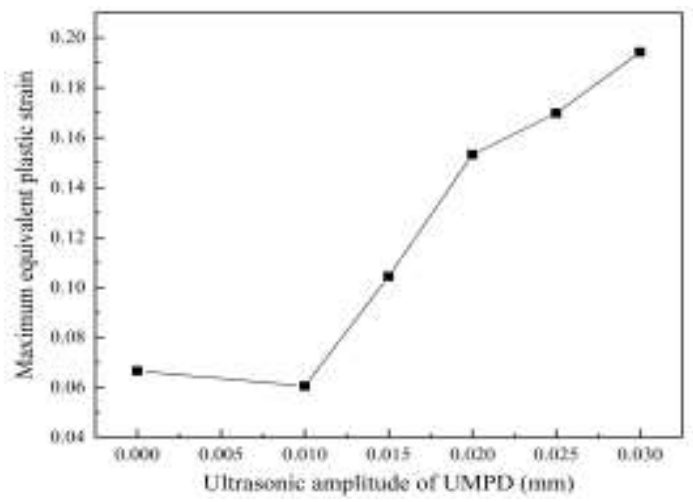

(b)

Fig. 10 Maximum stress and maximum equivalent plastic strain when the ultrasonic amplitude of the UMPD changes: (a) The relationship between the maximum stress 
and the amplitude of the UMPD; (b) The relationship between the maximum equivalent plastic strain and the amplitude of UMPD

After the profile is stretched and bent, due to the release of stress in the profile, the spring-back error will directly affect the quality of the formed part. In this paper, the displacement difference in the $\mathrm{y}$-axis direction is used as an index. Fig 11 is a schematic diagram of the process before and after the spring-back of the profile, in which the red line is the profile point for measuring the spring-back value. Fig 12 shows the resilience values of profile measurement points under different vibration frequencies.

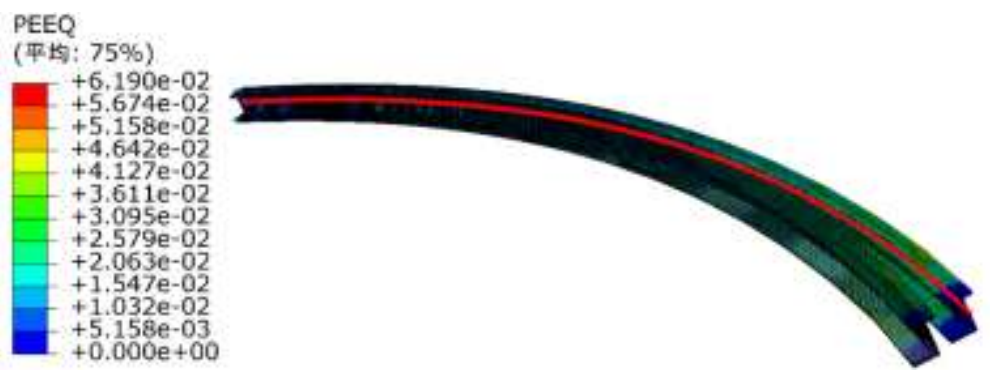

Fig. 11 Schematic diagram of profile spring-back measurement position

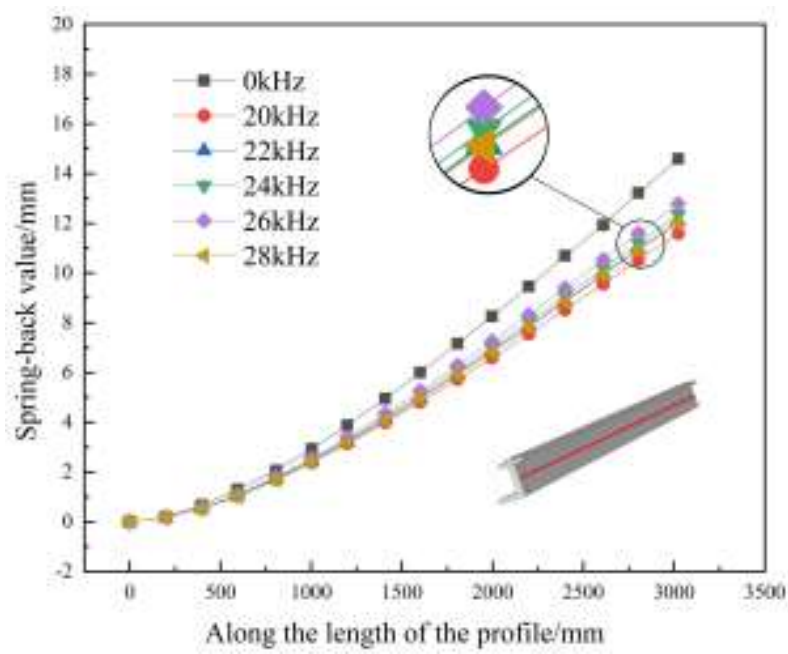

Fig. 12 Spring-back values of profiles with different ultrasonic frequencies

It can be seen that the spring-back value of the profile made by the ultrasonic-assisted stretch-bending process is lower than that of the profile without ultrasonic vibration. The end-point spring-back value of the profile processed by the ordinary MPD is $14.59 \mathrm{~mm}$, The end-point spring-back values of the profile under different vibration frequencies of the UMPD are 11.59, 12.08, 13.35, 12.78, and 12.02 
$\mathrm{mm}$, respectively, which decreased by $20.6 \%, 17.2 \%, 8.5 \%, 12.4 \%$, and $17.6 \%$. It can be seen from Fig 12 that within a certain range of ultrasonic vibration frequency, the effect of ultrasonic vibration frequency on suppressing the spring-back of the profile first increases and then decreases. It shows that excessive ultrasonic energy will improve the resilience of aluminum profiles. When the ultrasonic vibration frequency is too high, it may cause the parison bending failure, the stress concentration at the contact position of the mold and the parison, resulting in deformation instability and affecting the spring-back effect. Therefore, choosing the right ultrasonic vibration frequency helps to suppress the spring-back of the profile. Among them, the $20 \mathrm{kHz}$ ultrasonic vibration frequency has the best effect in suppressing the spring-back of the profile, which is reduced by $20.6 \%$ compared with the case without ultrasonic application. Ultrasonic-assisted vibration of the UMPD is beneficial to reduce the spring-back of the profile. This is because when the ultrasonic is applied to the mold head, the mold head will form a certain frequency of external excitation stress to act on the parison. Macroscopically, according to the theory of Wozney and Crawmer [18], when the stress in the profile itself is superimposed with the applied ultrasonic excitation stress, and the sum of the superposition is greater than the yield limit of the profile, the profile will undergo plastic deformation and release the residual stress. And eventually tend to a new balance, so the dimensional stability of the profile will be significantly improved.

The ultrasonic amplitude of the MPD at $20 \mathrm{kHz}$ vibration frequency is $0.01,0.015$, $0.02,0.025$, and $0.03 \mathrm{~mm}$ for finite element simulation analysis. Fig 13 shows the resilience graphs of profiles without ultrasonic effect and with different ultrasonic amplitude values applied. It can be seen from Fig 13 that the spring-back value of the profile made by the ultrasonic-assisted stretch-bending process is reduced overall compared with the ordinary profile. The end-point spring-back value of the profile processed by the ordinary MPD is $14.59 \mathrm{~mm}$, while the UMPD has different amplitudes. The end-points spring-back values of the profiles are 12.17, 11.75, 11.59, 11.63 and $11.68 \mathrm{~mm}$, which are reduced by $16.6 \%, 19.5 \%, 20.6 \%, 20.3 \%$ and $19.9 \%$. Therefore, changing the amplitude of ultrasonic vibration reduces the spring-back of 
the profile to different degrees, and the ultrasonic amplitude of $0.02 \mathrm{~mm}$ has the best effect on suppressing the spring-back of the profile, which is reduced by $20.6 \%$ compared with the case of no ultrasonic application. This is owing to the stress in the profile itself, and the dislocation will block up during the movement of the crystal, which will hinder the continuous movement of the dislocation. The purpose of ultrasonic vibration is to apply energy to promote the movement of dislocations and reduce the spring-back of the profile. When there is no external load, impurities and other precipitated phases in the material will hinder the movement of dislocations and form a cluster of dislocations. When ultrasonic vibration is applied, the forming will cause the dislocation to move under the action of the stress field, which can also promote the movement of the dislocation while generating the dislocation, so that the dislocation increases the driving force on the basis of the original movement and opens the position. The dislocation accumulation group promotes the continuous movement of dislocations so that the residual stress inside the material is released, and the profile is also transformed from elastic deformation to plastic deformation. The stability of the final material increases and the spring-back rate decreases. Therefore, the application of ultrasonic action during the stretching and bending of the profile can promote its creep deformation, and the ability of the elastic deformation of the profile to be transformed into plastic deformation is improved, which is conducive to the reduction of the resilience rate.

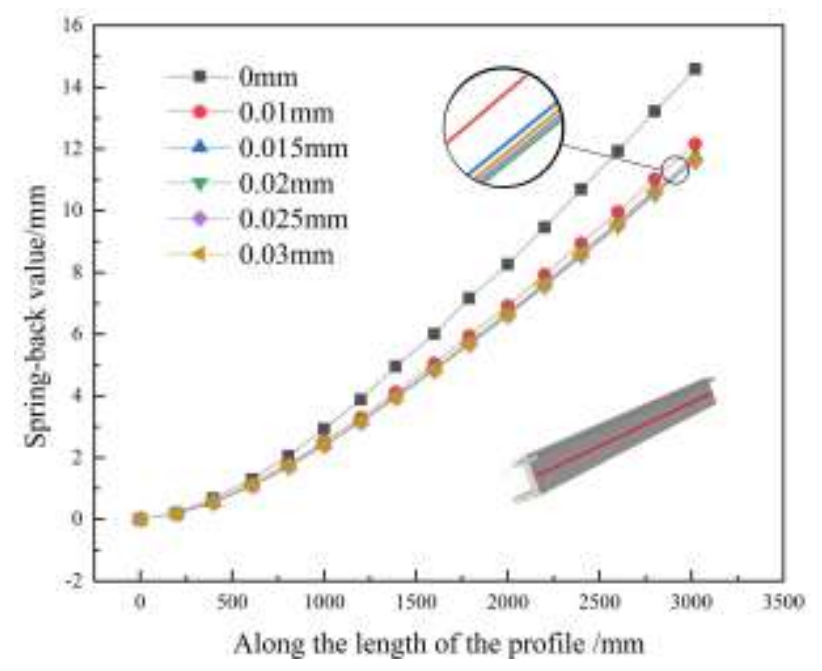

Fig. 13 Spring-back values of profiles with different ultrasonic amplitudes 


\section{Experimental verification}

In order to verify the accuracy of the numerical simulation analysis results, 22 aluminum profile samples with the same material parameters, cross-sectional shape and length as in Section 2.2 were selected, and 22 "L"-shaped cross-sectional profile tensile and bending tests were carried out. The test process is shown in Fig 14. When the forming is finished, unloaded the force, and used the spring-back detection tool to measure the spring-back of the profile part. The spring-backs of these points in the test and simulation models are measured respectively, and the average spring-backs of these points are also obtained. The comparison between the test results and the simulation results is shown in Fig 15. It is shown that the resulting trend of the tensile-bending experiment is consistent with the resulting trend of the finite element simulation. The ultrasonic vibration auxiliary process can reduce the spring-back rate of the profile and improve the shape accuracy of the part.
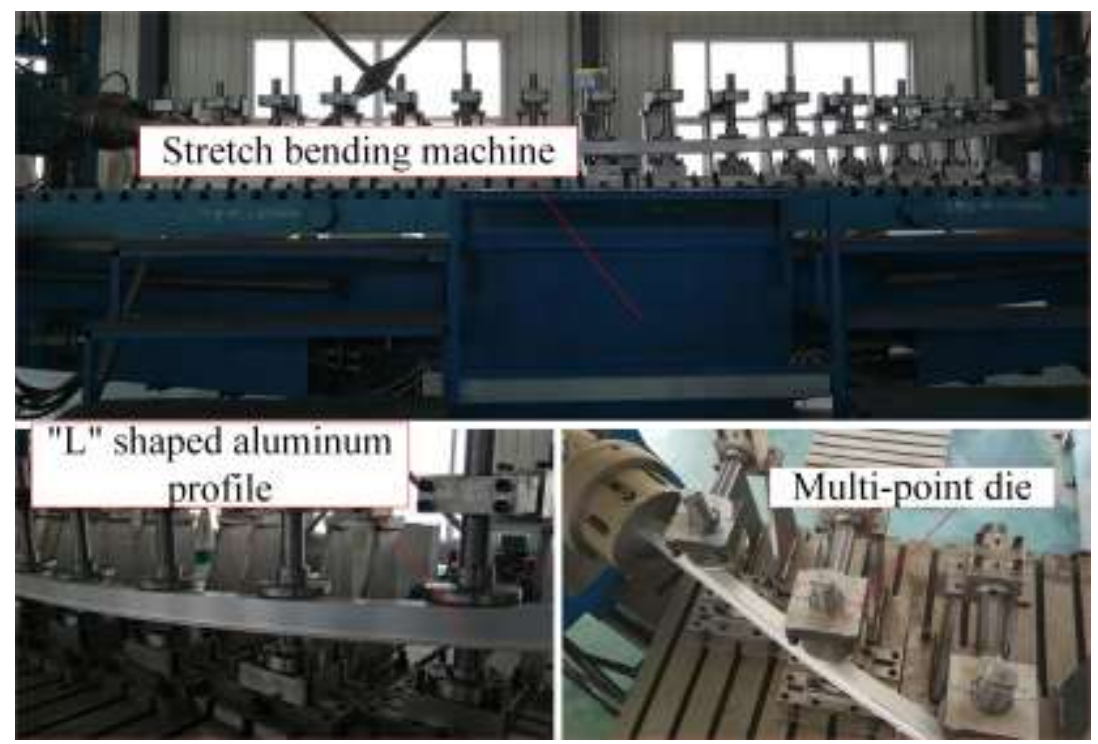

Fig. 14 Flexible tensile bending test of profile with L-section profile 


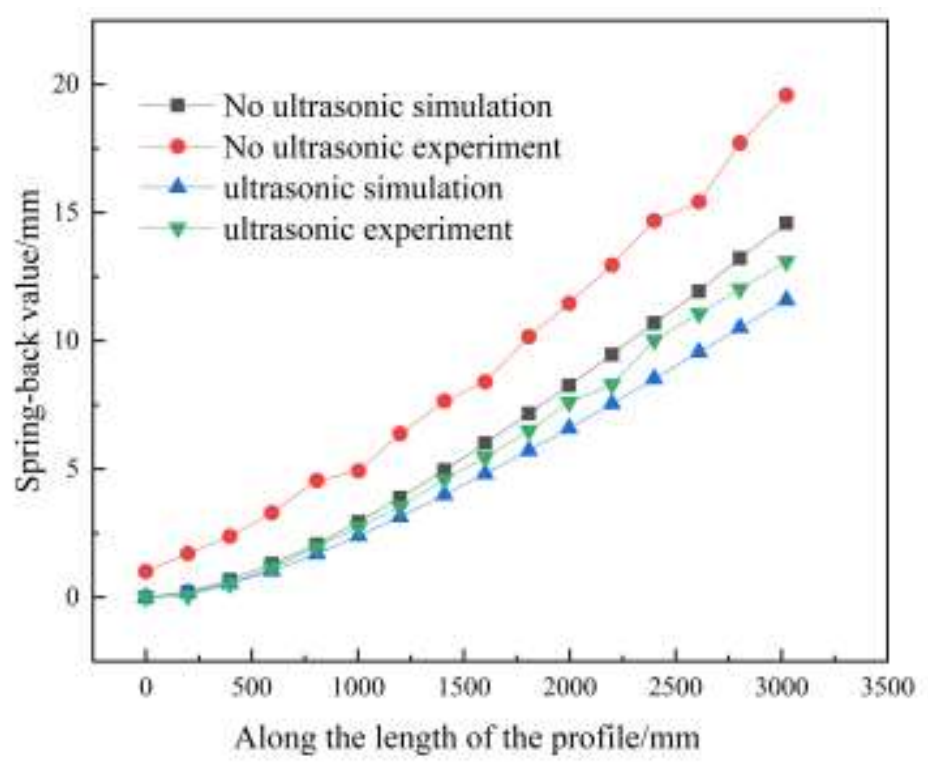

Fig. 15 Comparison of experimental results and numerical simulation results

\section{Conclusion}

(1) The ultrasonic vibration-assisted stretch-bending process can reduce the stress of the profile during the plastic deformation stage, and make the stress-strain distribution of the aluminum profile more uniform.

(2) The ultrasonic vibration-assisted stretch-bending process is beneficial to reduce the resilience of the profile. Different sizes of ultrasonic vibration frequencies can reduce the resilience of the profile to varying degrees. The $20 \mathrm{kHz}$ ultrasonic vibration frequency has the best effect on suppressing the resilience of the profile, which is better than no application. The ultrasound situation was reduced by $20.6 \%$.

(3) The change of the ultrasonic vibration amplitude of the mold reduces the spring-back of the profile to different degrees, and the ultrasonic amplitude of $0.02 \mathrm{~mm}$ has the best effect on suppressing the spring-back of the profile.

(4) A flexible multi-point tensile bending test was carried out on the "L"-shaped aluminum profile. The test results show that the experimental results are basically consistent with the simulation results, and the changing trend of spring-back deformation is consistent. For this reason, the molding parameters can be optimized through finite element simulation to guide production tests and reduce production costs. 


\section{Declarations}

Funding: This work was financially supported by the Project of Jilin Provincial Scientific and Technological Department (20190302037GX); the China Postdoctoral Science Foundation (2017M611321).

Conflicts of interest: The authors declare that they have no conflicts of interest.

Availability of data and material: The datasets used or analysed during the current study are available from the corresponding author on reasonable request.

Code availability: Not applicable.

Authors' contributions: Yi Li, and Zhiheng $\mathrm{Hu}$ developed the idea of the study and contributed to the acquisition and interpretation of data; Jicai Liang, and Ce Liang participated in its design and coordination and helped to draft the manuscript; Ce Liang provided critical review and substantially revised the manuscript. All authors read and approved the final manuscript.

\section{References}

1. Wang SH, Cai ZY, Li MZ (2000) Numerical simulation of multi-point stretch-bending forming of aluminum alloy profiles. Forging Technology 35(002):66-70

2. Wan M, Hong ZJ, Li WD et al (2008) Research on finite element simulation technology of stretch-bending forming of large profiled materials. Forging Technology 33(5):160-163

3. Zhu ZG, Yang XH (2008) Mathematics and mechanics analysis of the stretch-bending process. Forging Technology 32(3):152-154

4. Ji CQ, Li MZ, Cai ZY, et al (2007) Numerical simulation and formability comparison of multi-point forming and die forming processes for thin plates. Journal of Plasticity Engineering (05):48-51

5. Cai ZY, Li MZ, Lan YW (2012) Three-dimensional sheet metal continuous forming process based on flexible roll bending: principle and experiments. J Mater Process Technol 212:120-127

6. Cai ZY, Wang SH, Xu XD, Li MZ (2009) Numerical simulation for the multi-point 
stretch forming process of sheet metal. J Mater Process Technol 209(1):396-407

7. Li Y, Shi Z, Rong Q, Zhou W, Lin J (2019) Effect of pin arrangement on formed shape with multi-point flexible tool for creep age forming. Int J Mach Tool Manu $140: 48-61$

8. Zhou ZH, Cai ZY, Li MZ (2005) Stretching process and numerical simulation of multi-point die. Journal of Jilin University: Engineering Edition 35(3):287-291

9. Yuan YN (2017) Research on the Ultrasonic Vibration Punching Mechanism of 6061 Aluminum Alloy Sheet. Yanshan University.

10. He Q, Wen BC (1999) The progress and some problems of vibration plastic processing. Journal of Liaoning Institute of Technology 19(4):5-9

11. Rasoli M A, Abdullah A, Farzin M, et al (2012) Influence of ultrasonic vibrations on tube spinning process. Journal of Materials Processing Technology 212(6):1443-1452

12. Dutta R K, Petrov R H, Delhez R, et al (2013) The effect of tensile deformation by in situ ultrasonic treatment on the microstructure of low-carbon steel. Acta Materialia 61(5):1592-1602

13. Dutta RK, Petrov RH (2015) Hermans Accommodation of Plastic Deformation by Ultrasound-Induced Grain Rotation. Metallurgical and Materials Transactions A-PHYSICAL METALLURGY AND MATERIALS SCIENCE 46(8):3414-3422.

14. Wen T, Wang SQ, Gao F (2013) Blanking force and deformation characteristics of AZ31 and 5052 plates under high frequency vibration. Journal of Huazhong University of Science and Technology 41(8):87-91

15. Dnwson G R, Winsper C E, Sansome D H (1996) Application of High and Low Frequency Oscillations to the Plastic Deformation of Metal. Metal Forming 231(8): 234-3-238

16. Xiang Y, Vlassak J J (2005) Bauschinger effect in thin metal films. Scripta Materialia 53(2):177-182

17. Diao KS, Zhou XB, Jin CH (2003) Research progress on stretch-bending forming of aluminum alloy profiles. Journal of Plasticity Engineering (06):38-42 
18. Wozney G P, Grawmer G R (1968) An investigation of vibrational stress relief in steel. Welding Journal 47(9):411-419 


\section{Figures}

(a)

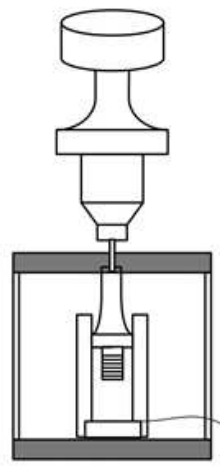

High frequency

power

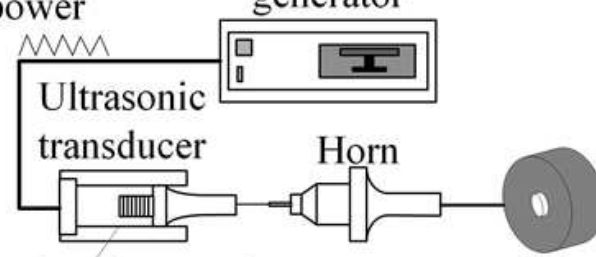

Piezoelectric ceramic crystal (b)

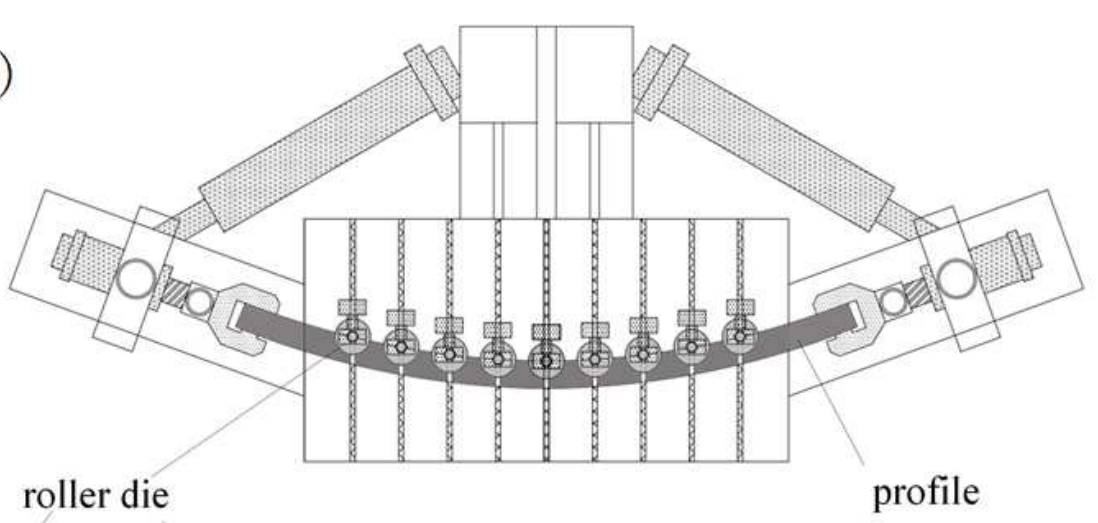

roller die

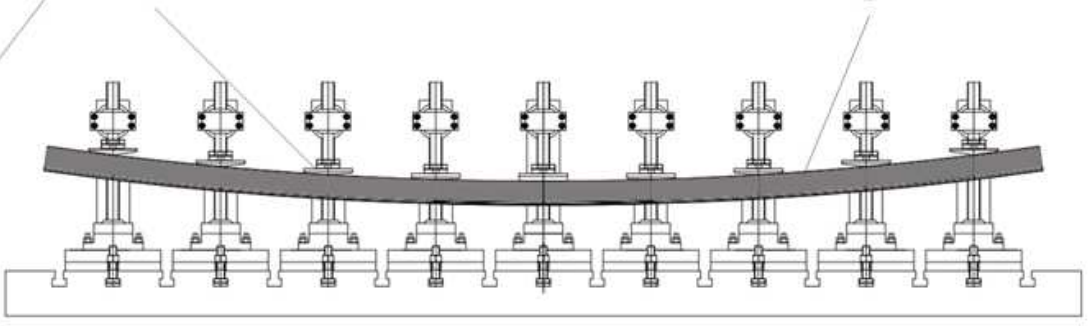

\section{Figure 1}

Schematic diagram of ultrasonic-assisted multi-point stretch-bending forming equipment: (a) Ultrasonic device and ultrasonic vibration principle; (b) Stretch-bending forming device 


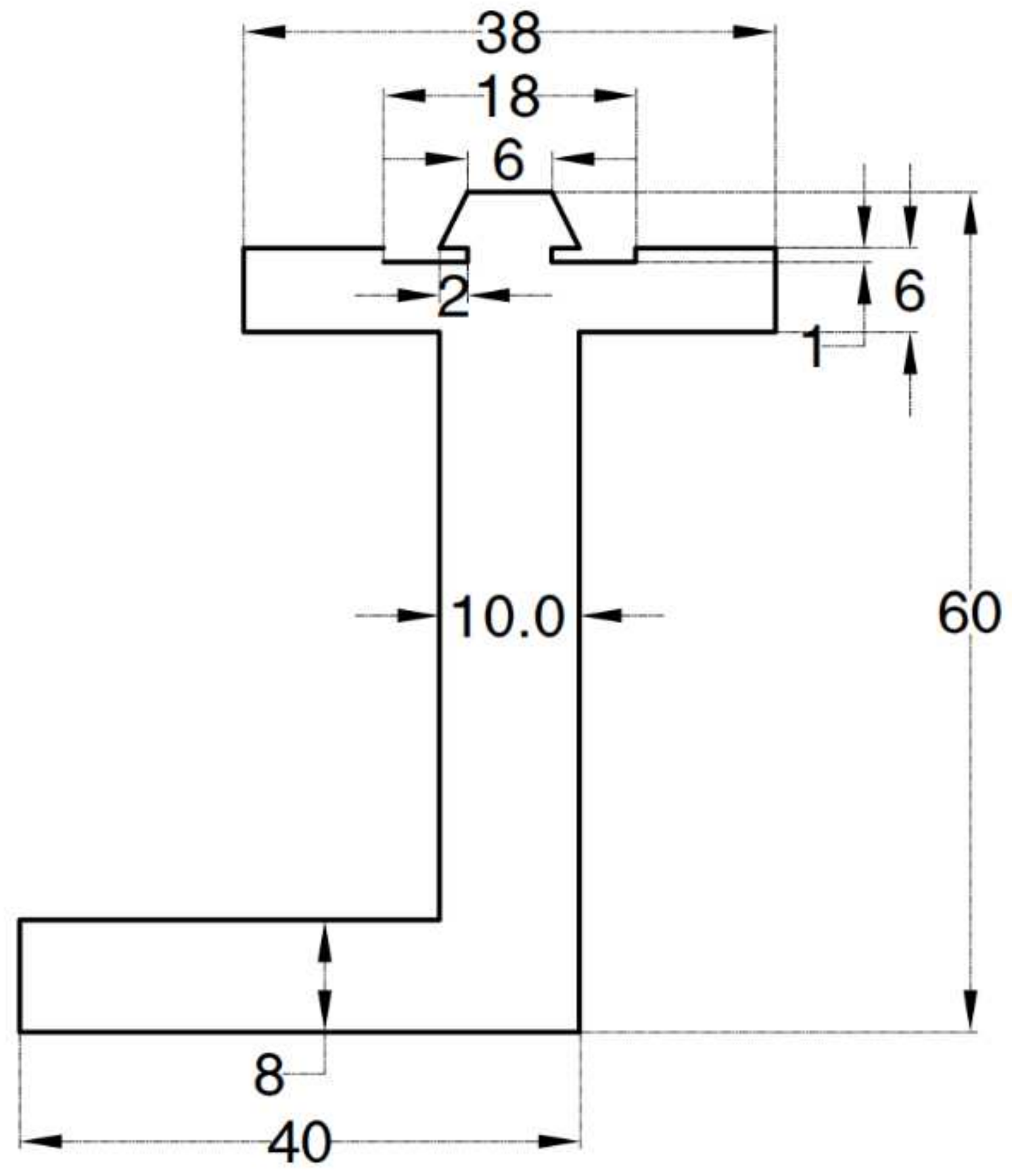

Figure 2

Geometric shape and size of L profile 


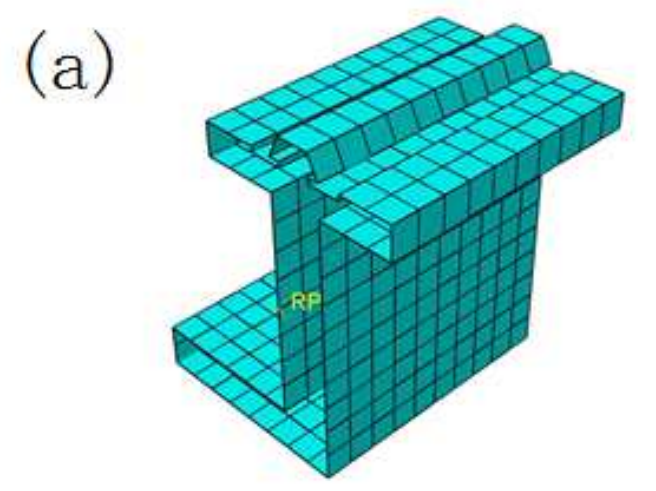

(c)

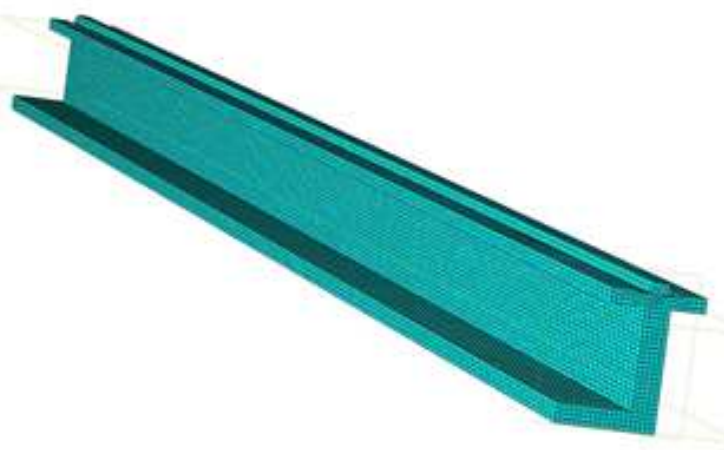

(b)

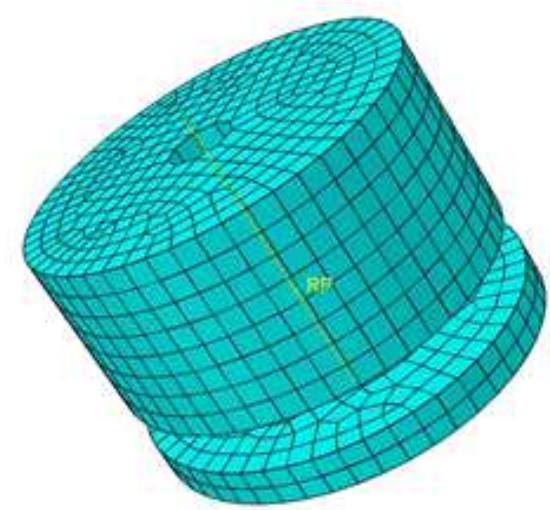

(d)

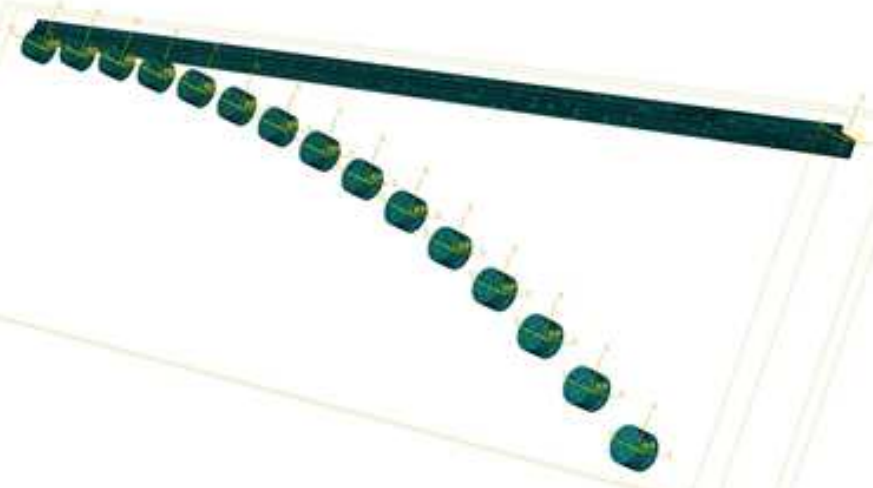

Figure 3

Main components: (a) clamp; (b) die; (c) aluminum profifile; (d) assembly 


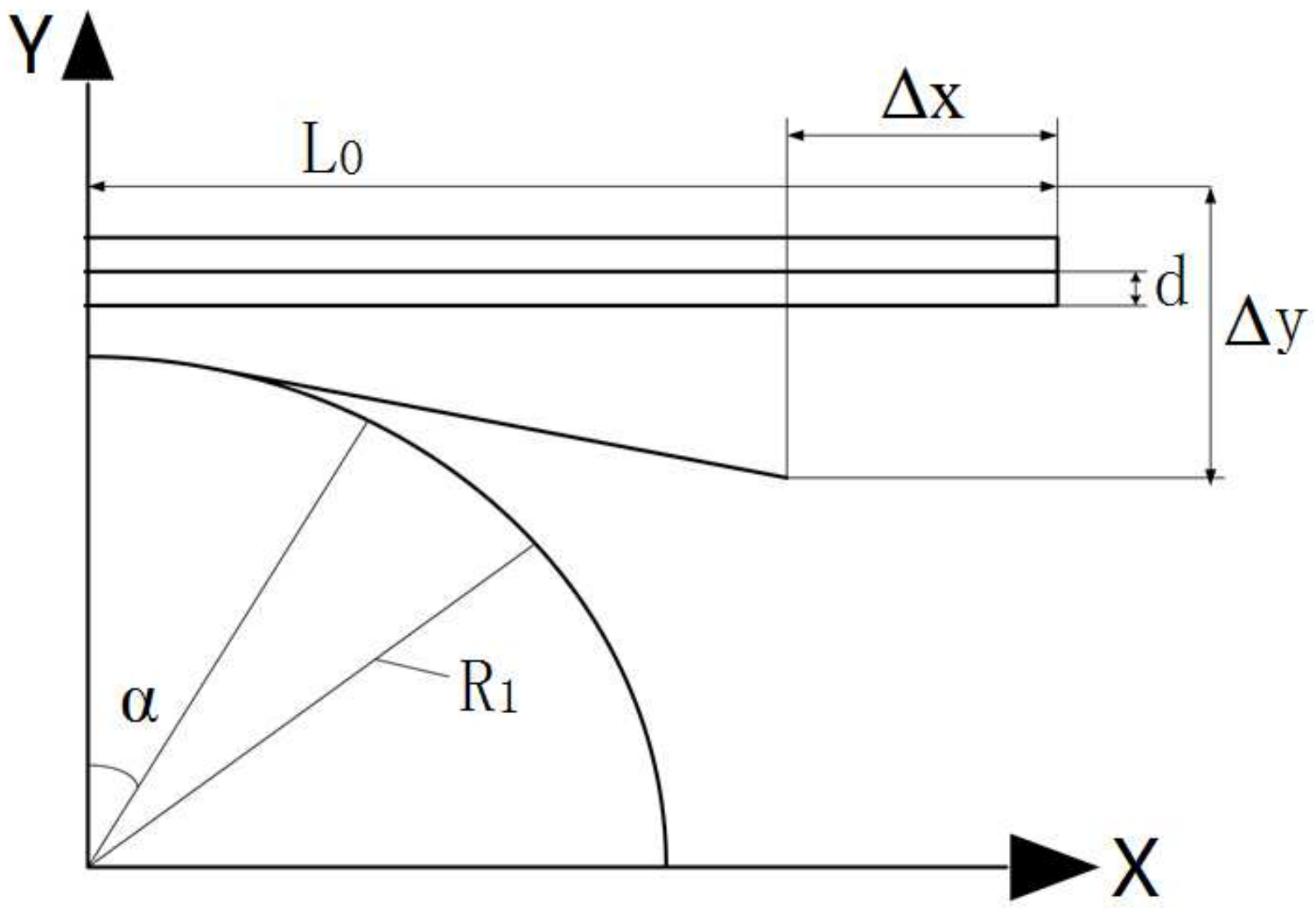

Figure 4

Profile movement trajectory

E

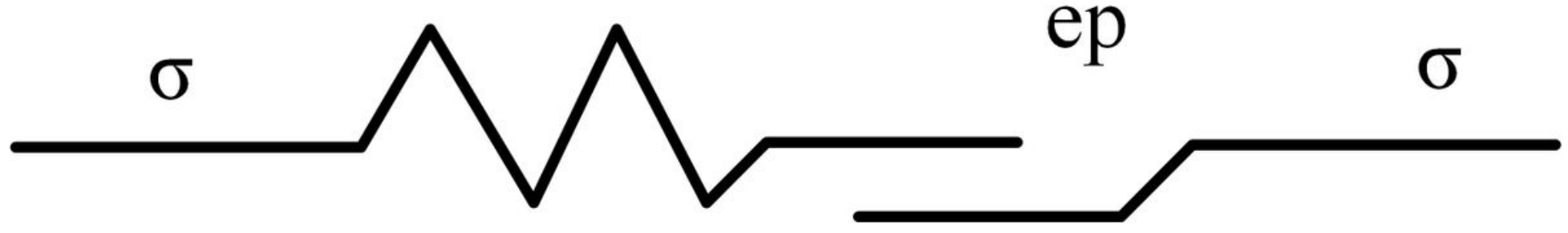

Figure 5

Elastic-plastic model 
(a)

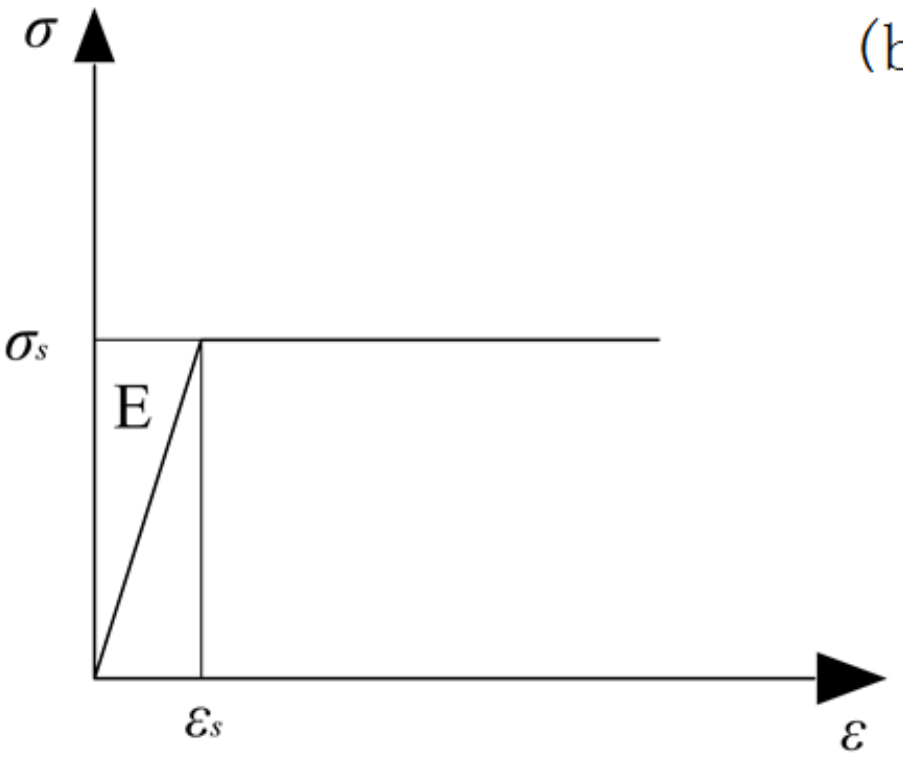

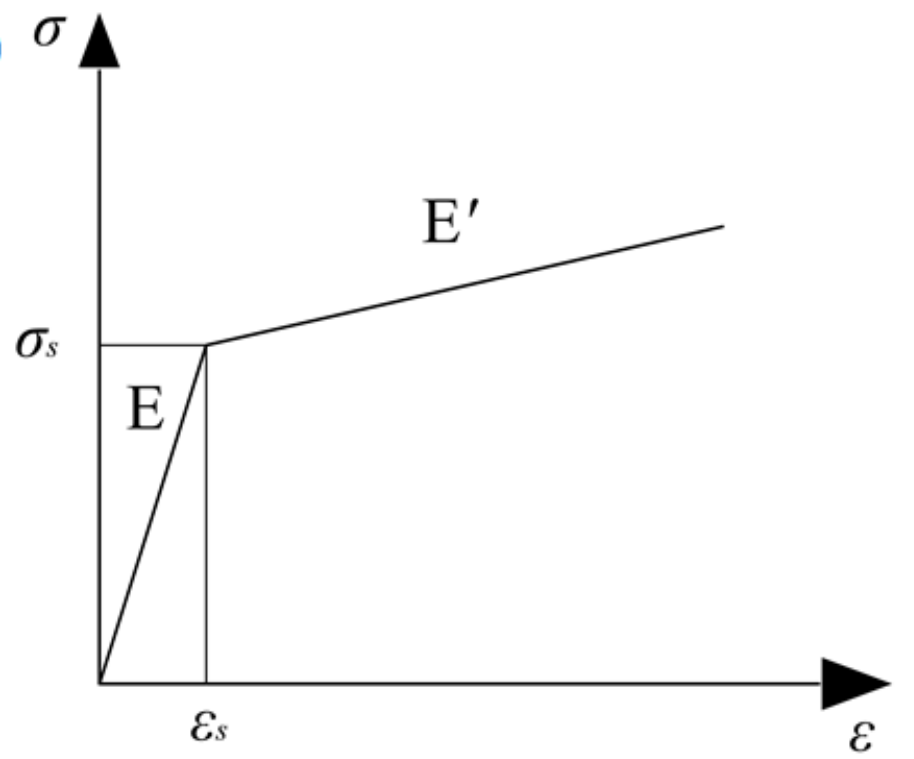

Figure 6

The stress-strain relationship between an ideal elastoplastic body (a) and a linearly strengthened elastoplastic body (b)

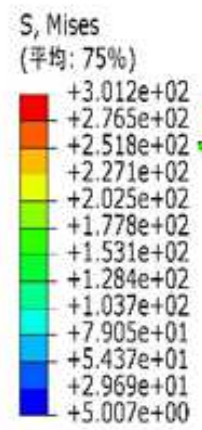

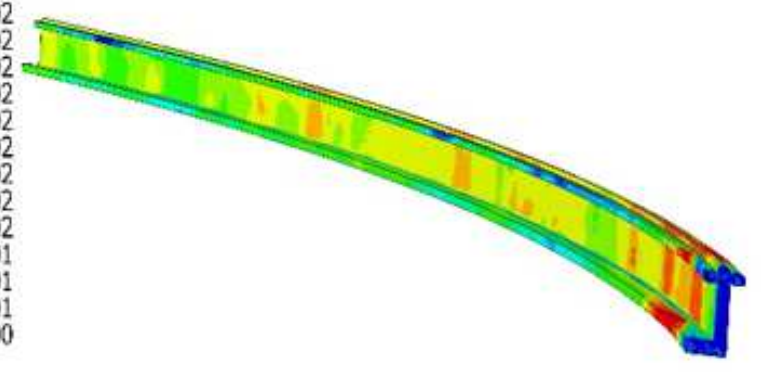

(a)

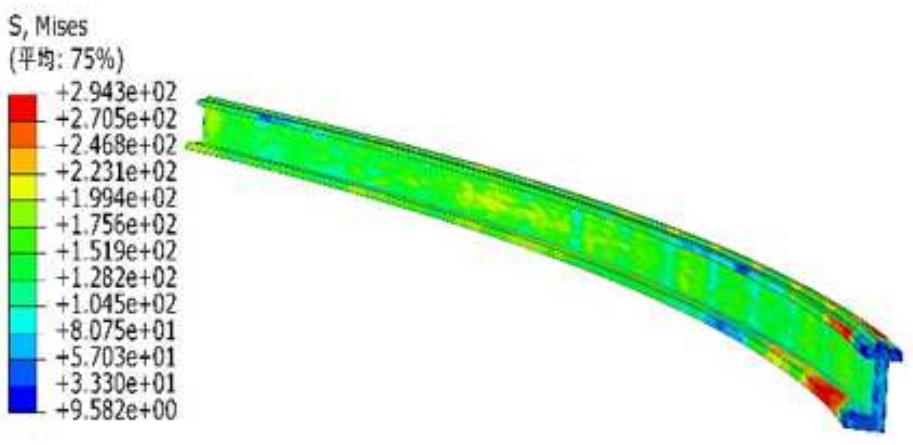

(b)

\section{Figure 7}

Stress distribution of the model after stretching and bending: (a) MPD forming; (b) UMPD forming

PEEQ

(平站: 75\%)

$+6.662 \mathrm{e}-02$

$+6.662 \mathrm{e}-02$
$+6.106 \mathrm{e}-02$
$+5.551 \mathrm{e}-02$
$+4.996 \mathrm{e}-02$
$+4.441 \mathrm{e}-02$
$+3.886 \mathrm{e}-02$
$+3.331 \mathrm{e}-02$
$+2.776 \mathrm{e}-02$
$+2.221 \mathrm{e}-02$
$+1.665 \mathrm{e}-02$
$+1.110 \mathrm{e}-02$
$+5.551 \mathrm{e}-03$
$+0.000 \mathrm{e}+00$

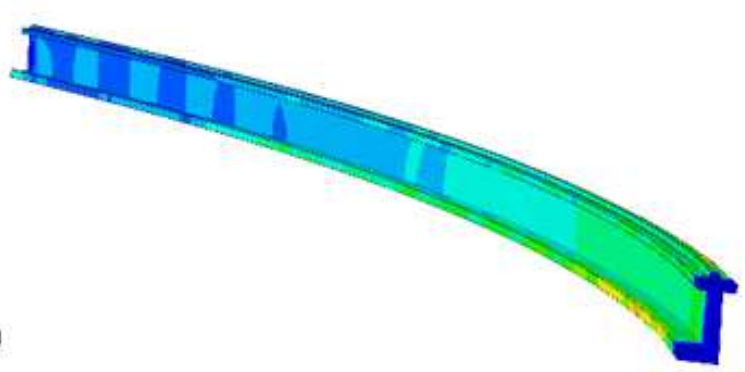

(a)
PEEQ

(平均: $75 \%$ )

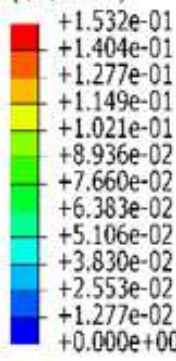

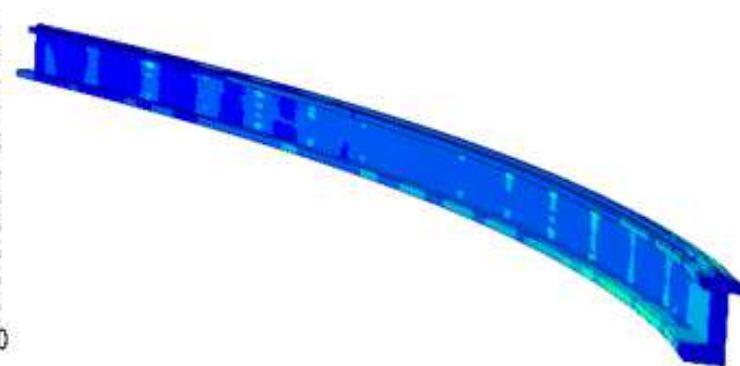

(b) 
Figure 8

The strain distribution of the model after stretching and bending: (a) MPD forming; (b) UMPD forming

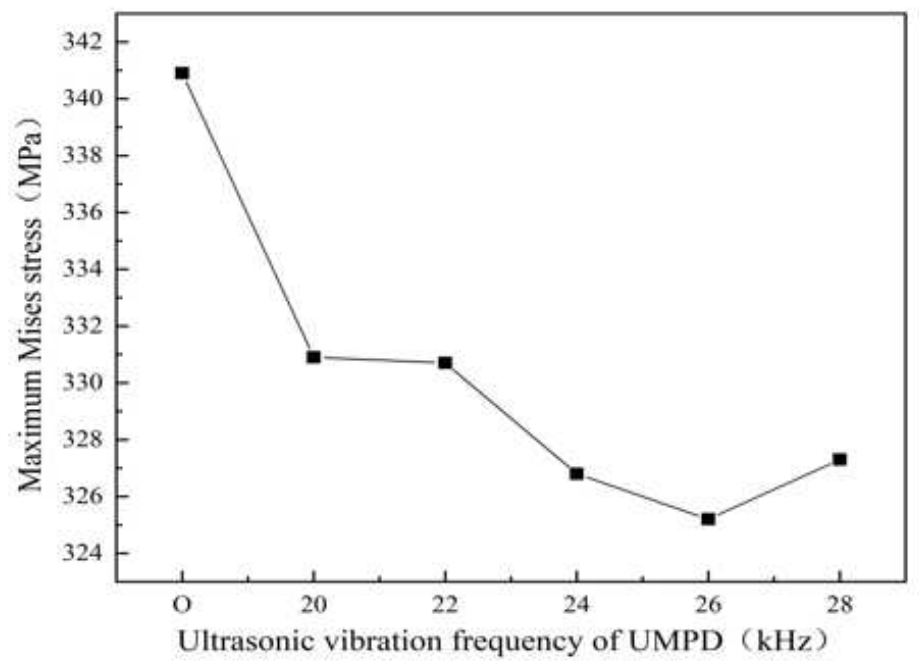

(a)

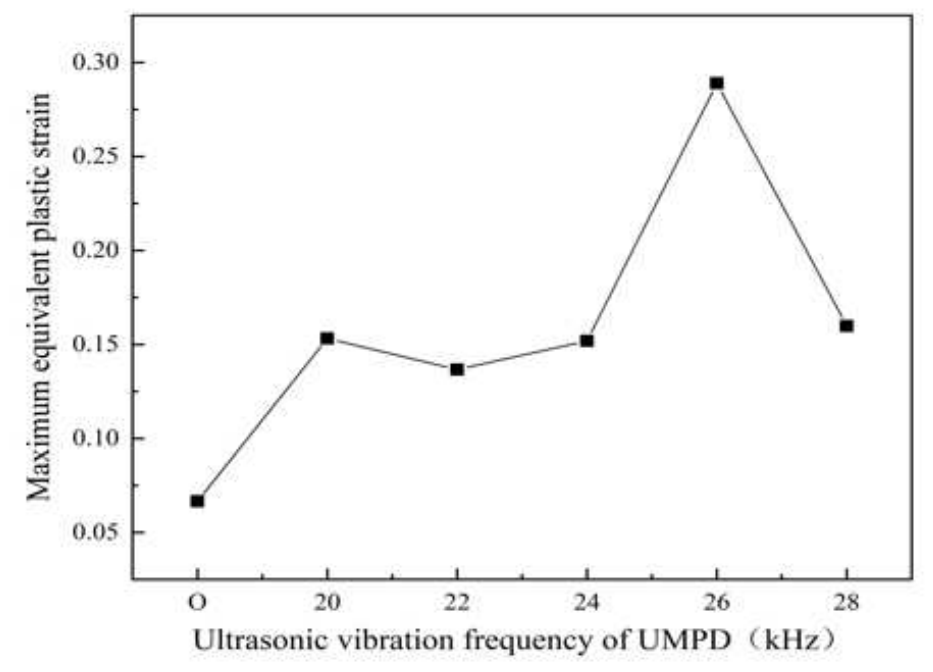

(b)

\section{Figure 9}

Maximum stress and maximum equivalent plastic strain when the ultrasonic vibration frequency of the UMPD changes: (a) The relationship between the maximum stress and the vibration frequency of the UMPD; (b) The relationship between the maximum equivalent plastic strain and the vibration frequency of the UMPD

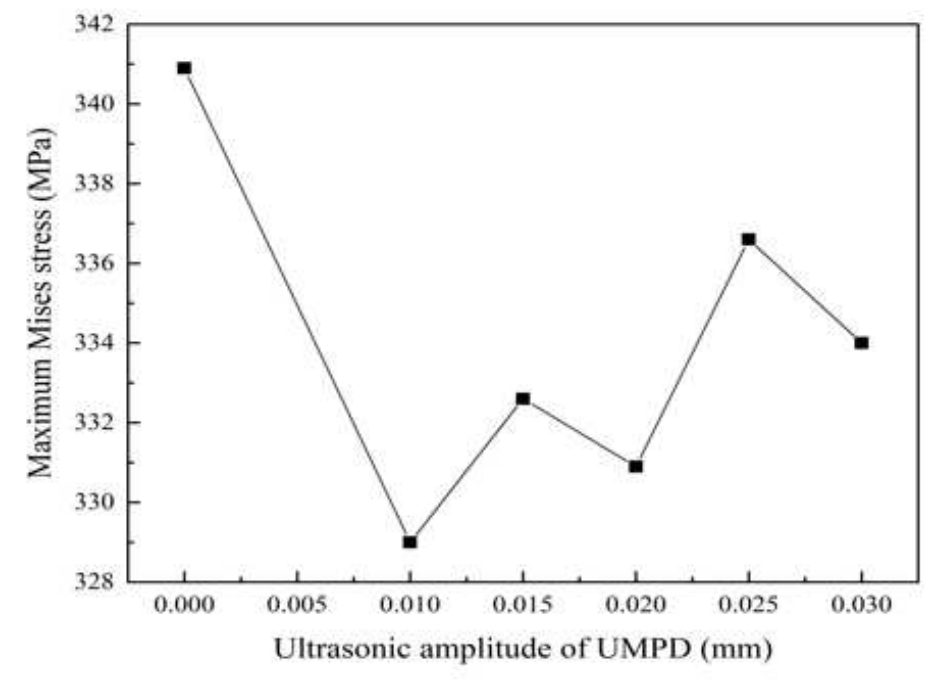

(a)

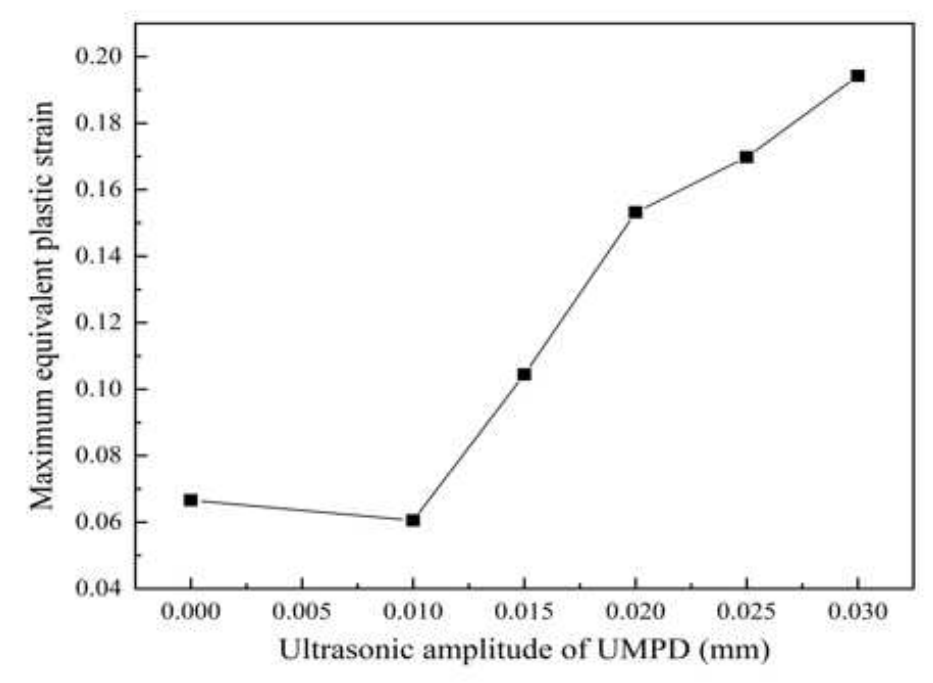

(b)

\section{Figure 10}

Maximum stress and maximum equivalent plastic strain when the ultrasonic amplitude of the UMPD changes: (a) The relationship between the maximum stress and the amplitude of the UMPD; (b) The 
relationship between the maximum equivalent plastic strain and the amplitude of UMPD PEEQ

(平均: $75 \%$ )
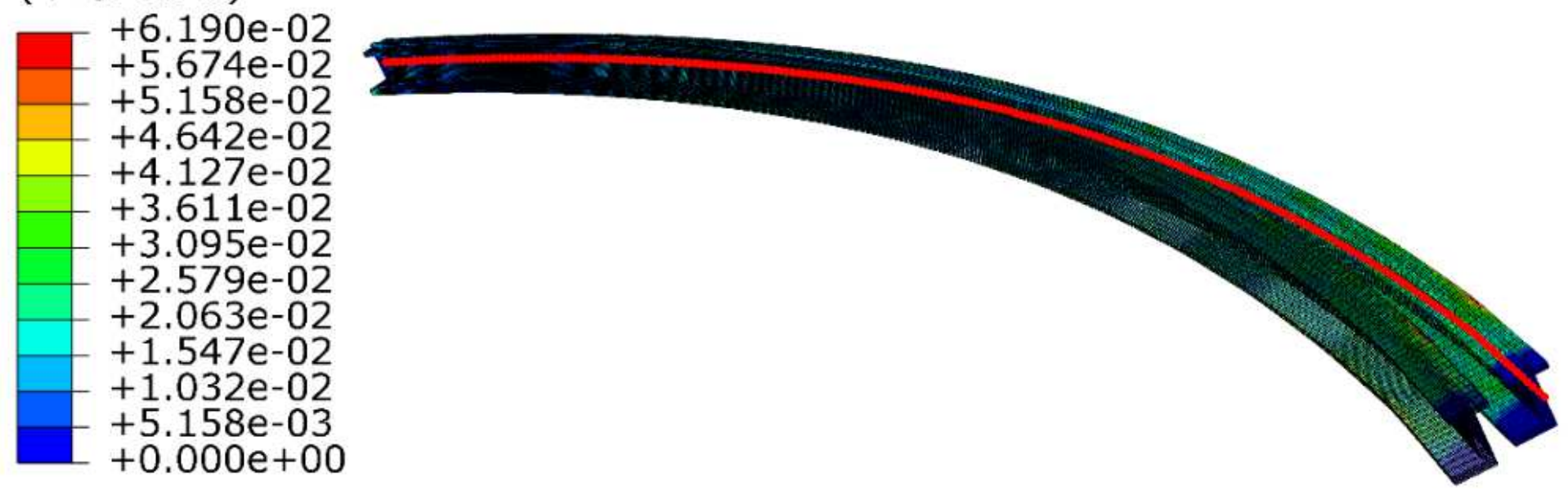

Figure 11

Schematic diagram of profile spring-back measurement position 


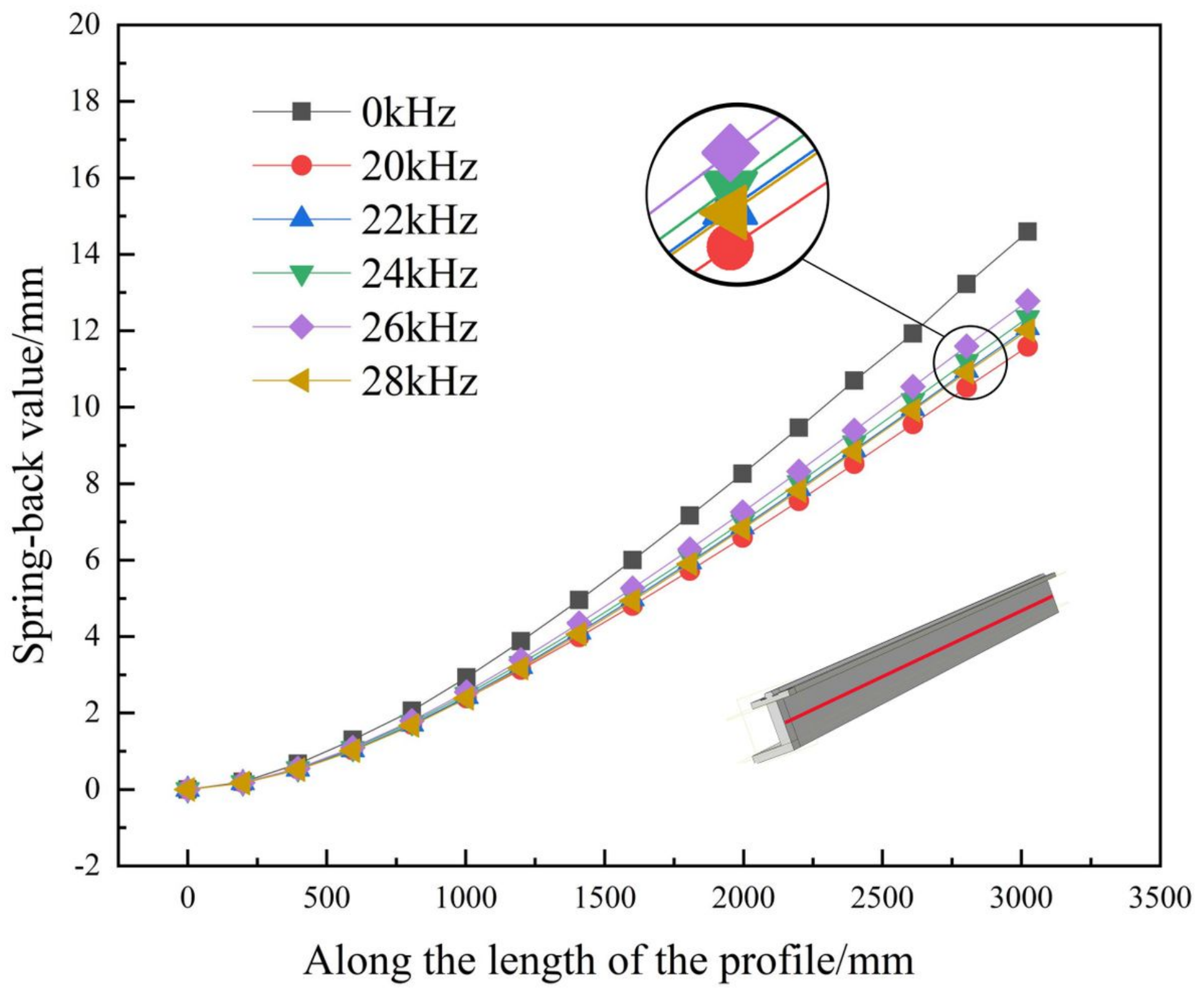

Figure 12

Spring-back values of profiles with different ultrasonic frequencies 


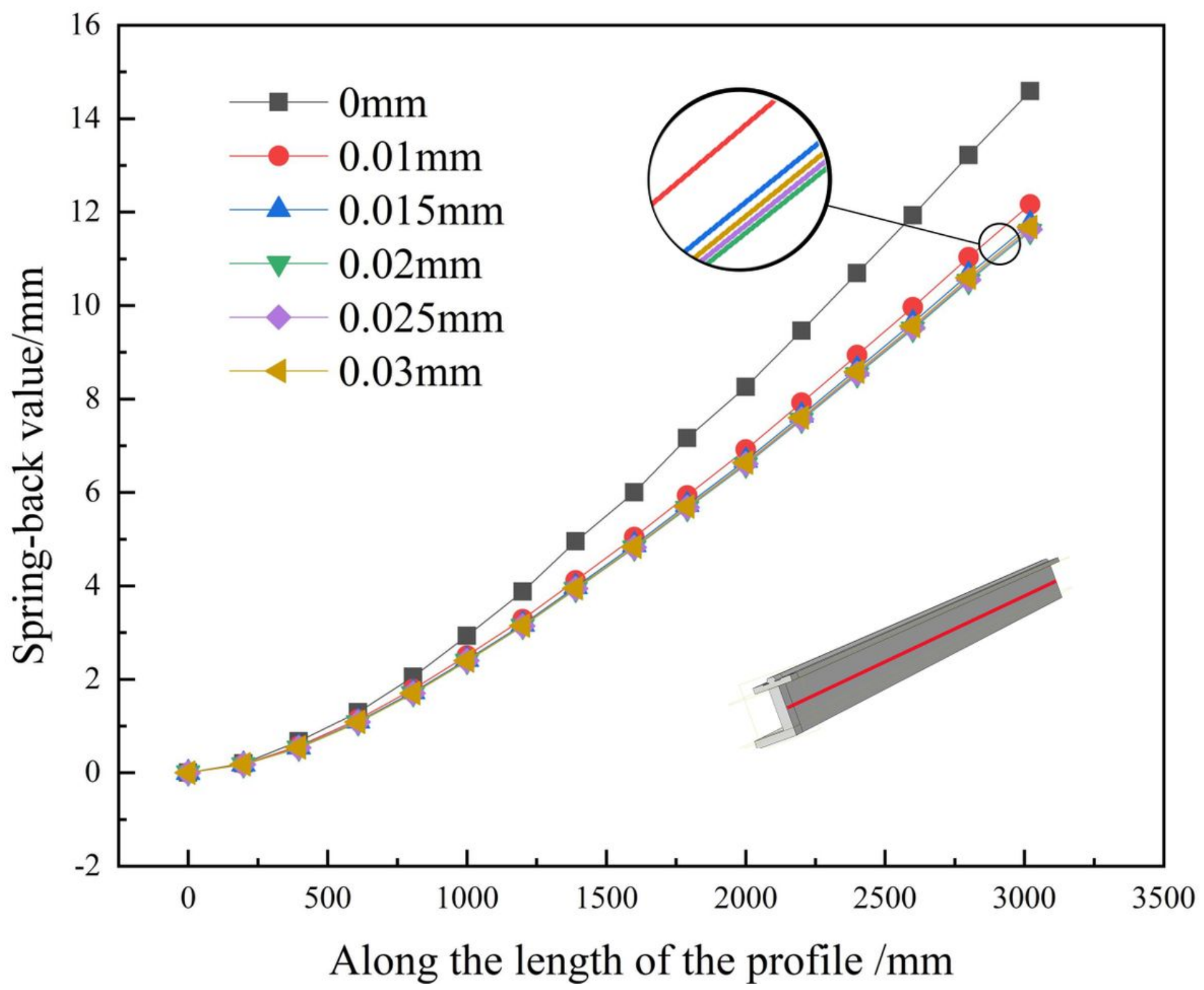

Figure 13

Spring-back values of profiles with different ultrasonic amplitudes 

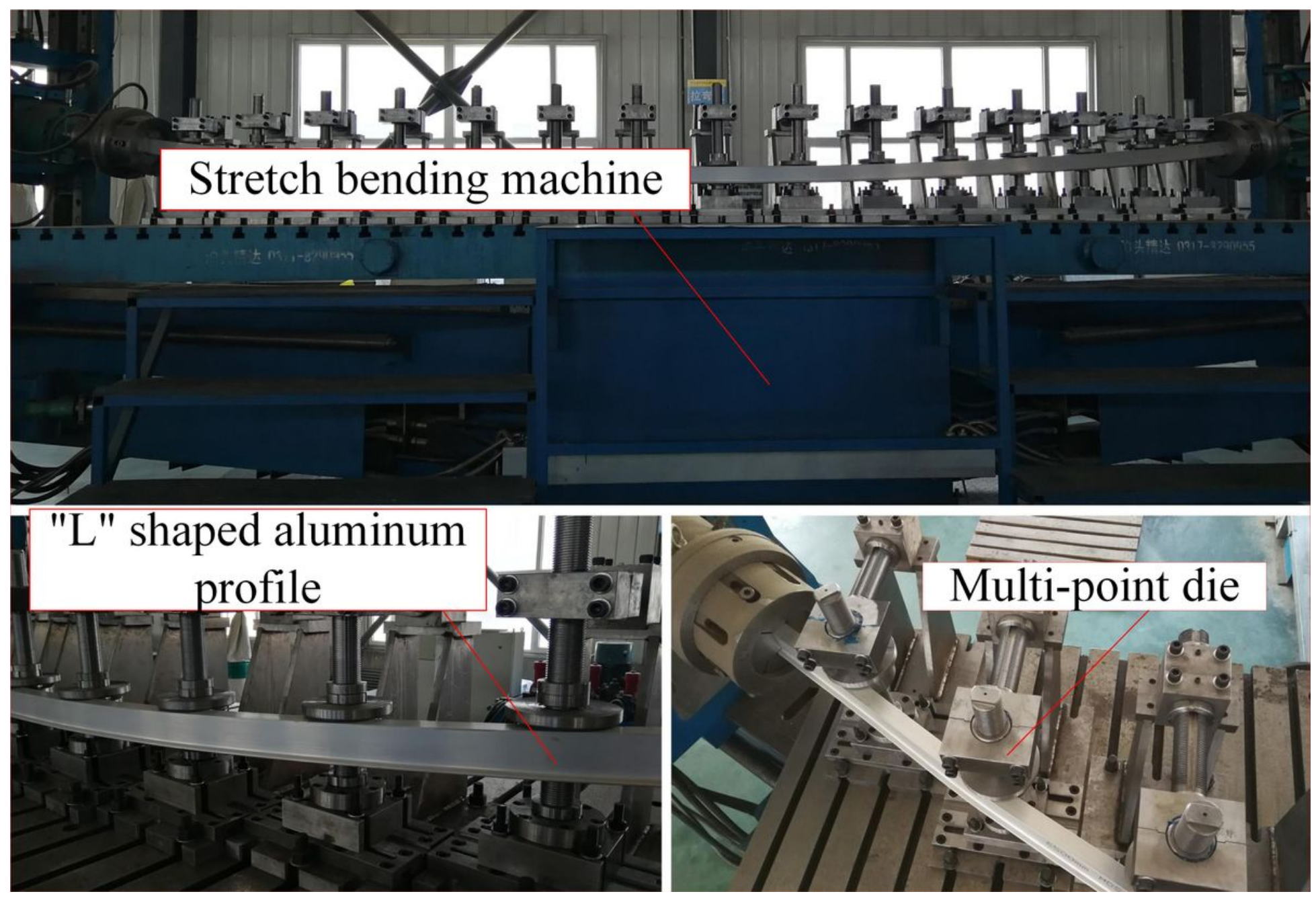

Figure 14

Flexible tensile bending test of profile with L-section profile 


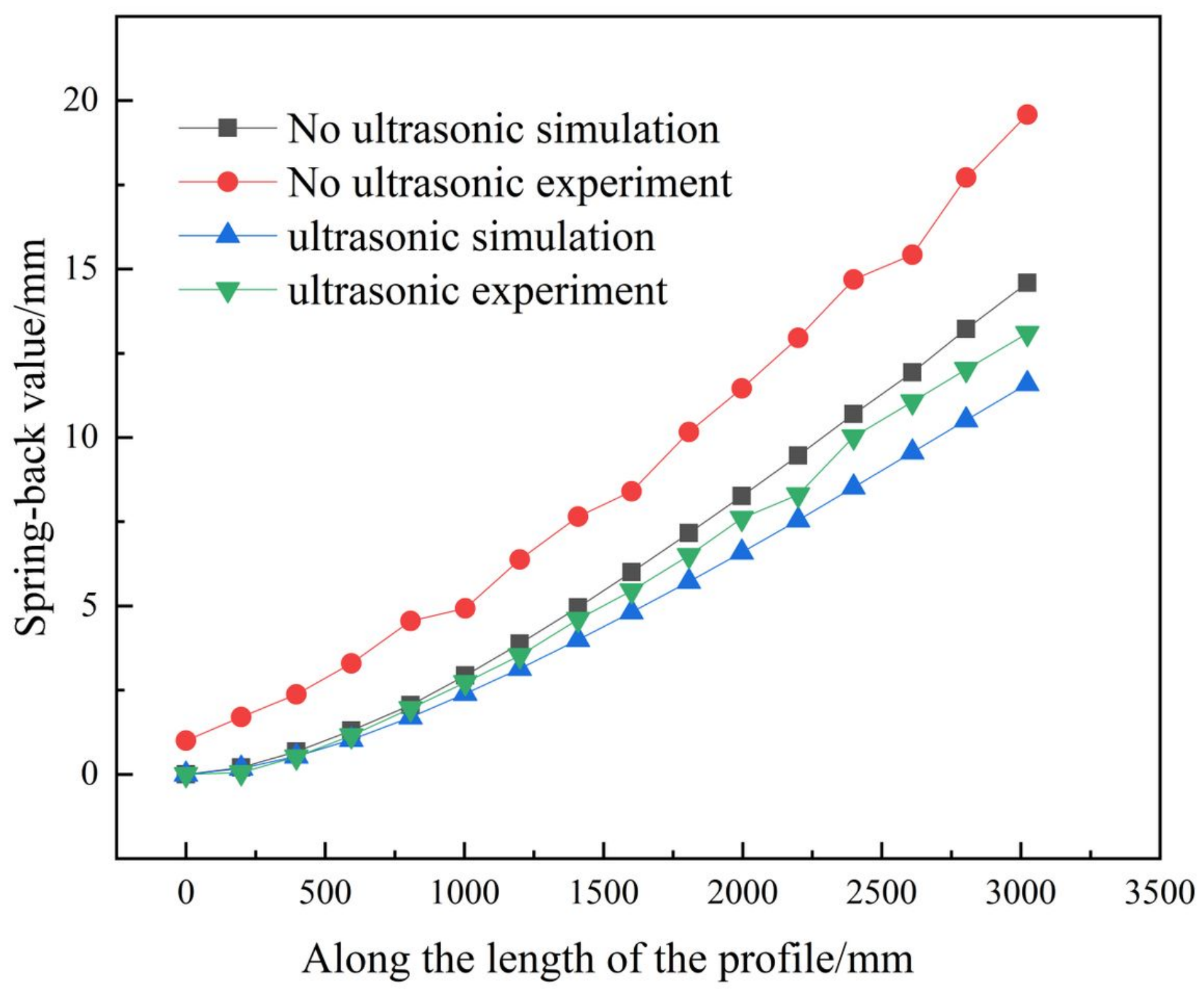

Figure 15

Comparison of experimental results and numerical simulation results 